\title{
WestVirginiaUniversity
}

THE RESEARCH REPOSITORY @ WVU

Graduate Theses, Dissertations, and Problem Reports

2004

\section{Sensitivity to molar contingencies of food presentation}

Jeffrey Everly

West Virginia University

Follow this and additional works at: https://researchrepository.wvu.edu/etd

\section{Recommended Citation}

Everly, Jeffrey, "Sensitivity to molar contingencies of food presentation" (2004). Graduate Theses, Dissertations, and Problem Reports. 698.

https://researchrepository.wvu.edu/etd/698

This Thesis is protected by copyright and/or related rights. It has been brought to you by the The Research Repository @ WVU with permission from the rights-holder(s). You are free to use this Thesis in any way that is permitted by the copyright and related rights legislation that applies to your use. For other uses you must obtain permission from the rights-holder(s) directly, unless additional rights are indicated by a Creative Commons license in the record and/ or on the work itself. This Thesis has been accepted for inclusion in WVU Graduate Theses, Dissertations, and Problem Reports collection by an authorized administrator of The Research Repository @ WVU. For more information, please contact researchrepository@mail.wvu.edu. 
Sensitivity to Molar Contingencies of Food Presentation

\author{
Jeffrey Everly \\ Thesis submitted to the Eberly College of Arts and Sciences at \\ West Virginia University \\ in partial fulfillment of the requirements for the degree of
}

\author{
Master of Arts \\ In \\ Psychology
}
Michael Perone, Ph.D., Chair Kennon A. Lattal, Ph.D.
Barry Edelstein, Ph. D.
Department of Psychology
Morgantown, West Virginia 2004

Keywords: molar, molecular, variable-time schedules, lever press, rat 


\section{ABSTRACT \\ Sensitivity to Molar Contingencies of Food Presentation \\ Jeffrey Everly}

Twelve rats were exposed to two variable-time schedules that differed in their rates of food delivery. The “imposed” schedule was normally in effect, but lever pressing occasionally switched to the "alternate” schedule for periods averaging 30 s. Increases in food frequency afforded by switching to the alternate schedule were manipulated across conditions. All rats were exposed to the same absolute food frequency increases, but the programming of these increases was varied among the rats by holding particular food delivery rates constant across conditions. For half of the rats, the schedules were signaled. In general, response rates were directly related to the size of the food-frequency increase, although the effect was more robust when the schedules were signaled. Response rates were undifferentiated when imposed schedule food delivery rates were held constant. The results lend limited support to the molar account that behavior is sensitive to changes in rates of stimulus events. 


\section{Acknowledgements}

I would like to begin by thanking the members of my committee. First and foremost, I thank Mike Perone, my advisor and chair of my committee. Mike continues to have a huge impact on my development both as a scientist and as a professional. I thank Andy Lattal for his insightful comments and questions. I thank Barry Edelstein for his valuable feedback and willingness to participate on short notice.

I would also like to thank other individuals who may not realize the importance of their contributions to this project. I thank Jessica Long, Melanie Holswade, and Adam Brewer for their willing, capable, and valuable assistance in collecting the data. I thank Tammy WadeGaluska and Chad Galuska for their guidance during my undergraduate career in the Perone lab. Finally, I thank my family for their enthusiasm and support throughout my graduate career 


\section{Table of Contents}

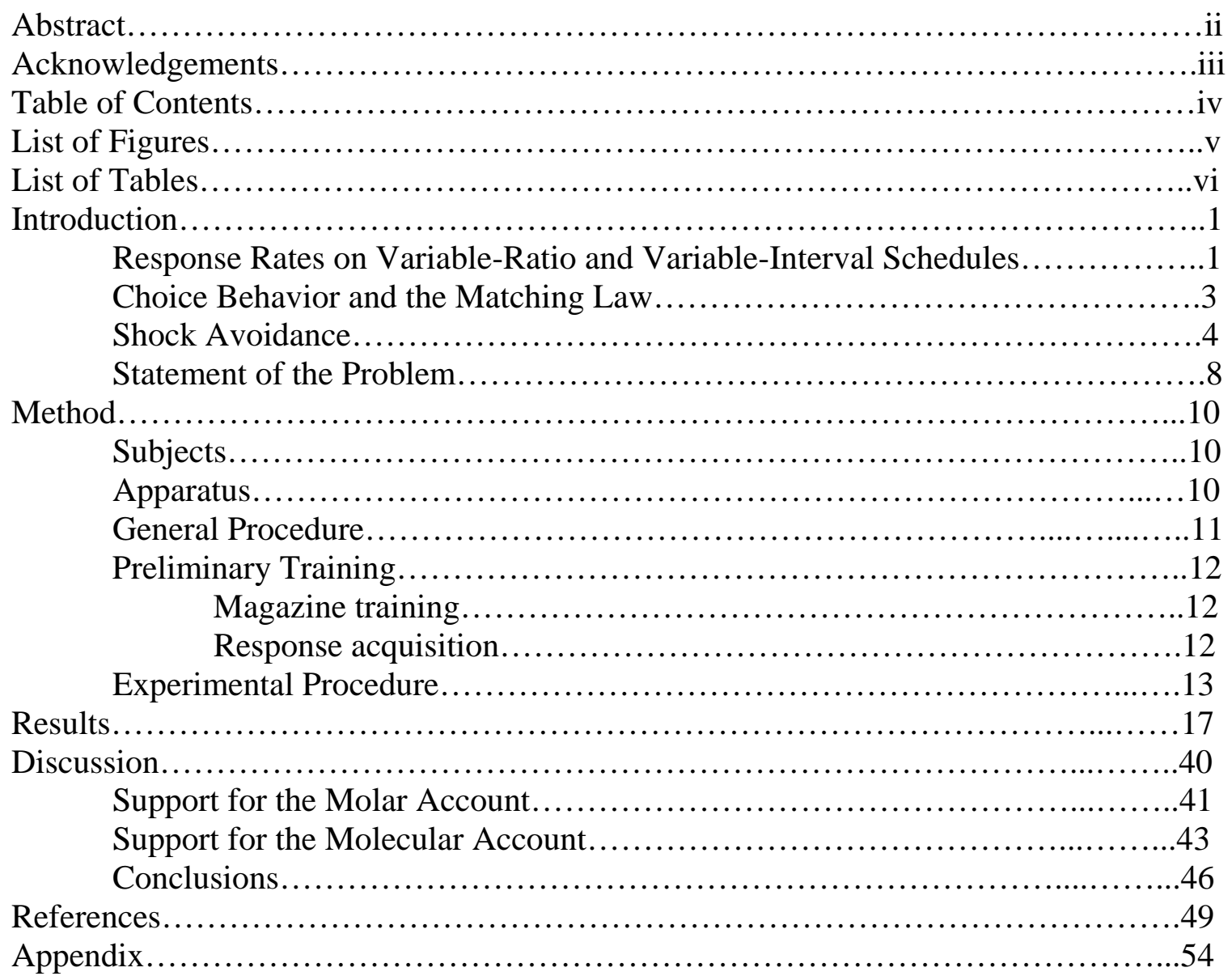




\section{List of Figures}

Figure 1. Scatterplot of the correlation between programmed and obtained food-frequency increase.

Figure 2. Relative response rates as a function of food-frequency increase.

Figure 3. Response rates on the imposed schedule as a function of food-frequency increas....25 Figure 4. Response rates on the imposed schedule as a function of food-frequency increase for all rats (top), the signaled and unsignaled groups (middle), and the Constant Overall, Constant

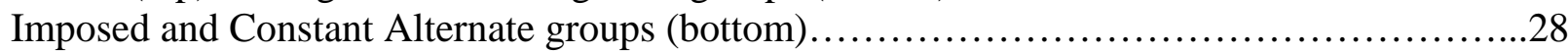
Figure 5. Response rates on the imposed schedule as a function of pellet rates on the imposed (top) and alternate (middle) schedules and overall pellet rates (bottom) for the Constant Overall

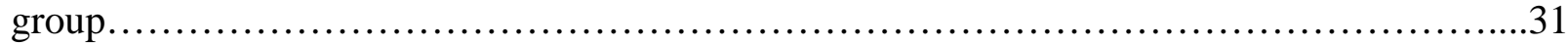
Figure 6. Response rates on the imposed schedule as a function of pellet rates on the imposed (top) and alternate (middle) schedules and overall pellet rates (bottom) for the Constant Imposed

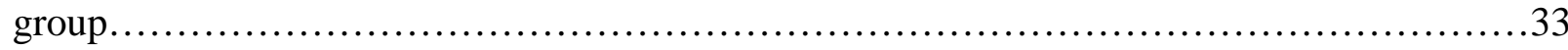

Figure 7. Response rates on the imposed schedule as a function of pellet rates on the imposed (top) and alternate (middle) schedules and overall pellet rates (bottom) for the Constant Alternate group

Figure 8. Response rates on the alternate schedule as a function of pellet rates on the alternate schedule. .36

Figure 9. Response rates on the imposed schedule as a function of relative food-frequency increase. 


\section{List of Tables}

Table 1. Order of conditions including the FFIs, imposed and alternate schedule pellet rates and VT values, overall pellet rates, and the number of sessions conducted for each condition.......15 Table 2. Programmed and obtained FFIs including the slope, intercept, and percentage of explained variance of the regression line for obtained FFIs..............................18

Table 3. Mean session time and proportion of the session spent on the alternate schedule.....21

Table 4. Programmed and relative FFIs for each Constancy Variable group...................38

Appendix. Programmed and obtained pellet rates for the imposed and alternate schedules......54 
Introduction

The probability of an instance of operant behavior is determined by the consequences that follow that behavior. There are two approaches to the exact nature of the control that consequences exert on behavior. The molecular approach emphasizes moment-to-moment relations between behavior and its consequences, particularly the temporal contiguity between the two. A molecular analysis would involve measurements that occur over time spans as brief as those involving a single instance of a behavior (e.g., Baum, 1973, 1989; Baum \& Davison, 2004). By comparison, the molar approach considers relations between behavior and consequences over an extended period of time. A molar analysis would examine behavioral control in terms of an aggregate of events where, for example, the rate at which behavior and consequences occur would be the critical variable (e.g., Baum, 1973, 1981, 1989; Baum \& Davison, 2004).

Experimental research has addressed the molar-molecular issue in the context of several topical areas within behavior analysis. Key concerns include the difference in response rates engendered by ratio and interval schedules (e.g., Reed, Soh, Hildebrandt, DeJongh, \& Shek, 2000; Baum, 1981), choice behavior as understood via the Matching Law (e.g., Herrnstein, 1997; Shimp, 1966), and shock avoidance (e.g., Dinsmoor, 2001; Herrnstein \& Hineline, 1966). These topics will be summarized below, and both molar and molecular accounts will be considered.

\section{Response Rates on Variable-Ratio and Variable-Interval Schedules}

Among the most commonly studied schedules of reinforcement are variable-ratio (VR) and variable-interval (VI) schedules. On VR schedules, reinforcement occurs after a number of responses that varies around some mean value. For example, on a VR-50 schedule, reinforcement occurs every 50 responses on average. On VI schedules, a response can only be 
reinforced after an interval has elapsed. The intervals vary around some mean duration. On a VI 50-s schedule, for example, reinforcement occurs following the first response after 50 s elapses on average. Across a wide variety of schedule values, it has been demonstrated that VR schedules produce higher response rates than VI schedules when the two schedules produce equal reinforcement rates (e.g., Baum, 1973, 1981).

To explain the differences in VR and VI response rates, the molecular approach appeals to the differential reinforcement of the times between responses, or interresponse times (IRTs). Because the likelihood of reinforcement on VI schedules increases as time passes, longer IRTs are reinforced more often than shorter IRTs because of the greater probability that a scheduled interval will elapse during longer IRTs (e.g., Baum, 1989; Platt, 1979). On VR schedules, Skinner (1938) observed that animals tend to emit bursts of rapid responding (a cluster of responses characterized by short IRTs) followed by brief pauses (longer IRTs). Because the number of shorter IRTs is greater than the number of longer IRTs, shorter IRTs have a higher probability of being selectively reinforced. The result of selectively reinforcing long IRTs on VI schedules is response rates that are lower than those on VR schedules, which engender higher response rates due to the selective reinforcement of short IRTs (e.g., Baum, 1989; Platt, 1979). Empirical support for this theory comes from experiments in which VI response rates were increased by manipulating reinforced IRTs (e.g., Platt 1979), and experiments in which reinforced IRTs on VR schedules were yoked to VI schedules, resulting in similar response rates between the two schedules (e.g., Peele, Casey, \& Silberberg, 1984).

To explain differences in VR and VI response rates, the molar approach derives feedback functions in which obtainable reinforcement rates are calculated as a function of response rates. On VR schedules, the relation between reinforcement rates and response rates is linear such that 
reinforcement rates increase as response rates increase. On VI schedules, the relation between reinforcement rates and response rates is negatively accelerated such that a point can be reached past which further increases in response rates will not produce further increases in reinforcement rates. Hence, the molar feedback an organism receives from reinforcement rates explains the differences in VR and VI response rates. On a VI schedule, the maximum reinforcement rate is attained at low response rates. On a VR schedule, there is no maximum reinforcement rate imposed by the schedule, and higher rates of responding will always lead to higher rates of reinforcement (e.g., Baum, 1981, 1989).

\section{Choice Behavior and the Matching Law}

Perhaps one of the most significant achievements of the molar approach was the formulation of the Matching Law (e.g., see Herrnstein, 1997). The Matching Law was derived from patterns of performance on concurrent VI VI schedules, a common procedure for studying choice. A typical arrangement involves two independently operating VI schedules that are simultaneously available. Literally hundreds of experiments have revealed that the allocation of responding across the two schedules is proportional to the distribution of reinforcers across the schedules (e.g., Herrnstein, 1997, 1961). The relation is embodied in the generalized Matching Law:

$$
\mathrm{B}_{1} / \mathrm{B}_{2}=\mathrm{k}\left(\mathrm{r}_{1} / \mathrm{r}_{2}\right)^{\mathrm{a}}
$$

where $B_{1}$ and $B_{2}$ are the number of responses on each of the schedules, $r_{1}$ and $r_{2}$ are the number of reinforcers obtained on each of the schedules, $k$ is a bias parameter indicating a constant tendency to allocate responses to a particular schedule, and $a$ is a parameter indicating the sensitivity of behavior to changes in the rates of reinforcement on the two options (Baum, 1974). The generalized Matching Law has been extended to a variety of reinforcement schedules (e.g., 
see Herrnstein, 1997) including single schedules of positive and negative reinforcement (e.g., see de Villiers \& Herrnstein, 1976). The Matching Law can be interpreted as meaning that the amount of behavior emitted on particular schedule is controlled by the obtained reinforcement rate on that schedule (e.g., Herrnstein, 1997).

Rather than looking at aggregates of response rates and reinforcement rates, a molecular analysis of performance on concurrent VI VI schedules looks at individual response-reinforcer relations. For example, Shimp $(1966,1969)$ reported evidence that an animal’s response allocation across concurrent schedules is based on short-term changes in the probability of reinforcement. Shimp used the term "momentary maximization” to describe the process whereby the animal tends to switch schedules when doing so is likely to be reinforced. By this account, molar matching is a by-product of the molecular process of momentary maximizing (e.g., Staddon, Hinson, \& Kram, 1981).

\section{Shock Avoidance}

Molar-molecular issues are not exclusive to schedules of positive reinforcement. These issues are also present in studies of negative reinforcement, or the maintenance of behavior by the removal, postponement, or cancellation of an aversive stimulus. There are several preparations for studying negative reinforcement. In Sidman’s (1953) free-operant avoidance procedure, shocks are delivered at regular intervals of, for example, $5 \mathrm{~s}$ in the absence of responding. Once a response is emitted, the next scheduled shock is postponed for an interval of, for example, $30 \mathrm{~s}$. Subsequent responding during the 30-s interval will postpone the next scheduled shock for an additional 30 s, though failure to respond during the 30 -s interval will resume shock delivery at 5-s intervals. Another avoidance procedure developed by de Villiers (1972) delivers shocks at variable intervals. Responding during a given interval cancels the next 
scheduled shock delivery. Both of these preparations are effective at maintaining avoidance responding (e.g., de Villiers, 1972; Sidman, 1953).

An interesting result of the aforementioned avoidance procedures is that responding necessarily reduces contact with the negative reinforcer (shock), which raises questions about the immediate consequences that maintain avoidance responding. The molecular approach explains this result in terms of two factors. One factor is Pavlovian conditioning, and the second factor is operant conditioning. One form of two-factor theory states that stimuli positively correlated with shocks become conditioned aversive stimuli via Pavlovian conditioning, and operant behavior that removes these stimuli is subsequently reinforced. For example, in Sidman's (1953) procedure, shocks occur at regular intervals in the absence of responding, hence the passage of time without a response may function as an aversive stimulus. Such a "conditioned aversive temporal stimulus” is removed by a response, which increases the temporal distance to the next scheduled shock. Hence, avoidance responding is reinforced by the removal of conditioned aversive temporal stimuli (Anger, 1963).

Another form of two-factor theory states that stimuli negatively correlated with shock become conditioned reinforcers for operant responding. In avoidance procedures, responses are followed by shock-free periods that are accompanied by stimuli produced by, for example, the lever press that cancels or postpones the shock. Such stimuli might include the movement of the lever or the sound of the lever as it is being pressed, and by being paired with the onset of a shock-free period, these stimuli become conditioned reinforcers for avoidance responses (Dinsmoor, 2002; Dinsmoor \& Sears, 1973).

According to the molar approach, it is not necessary to posit two factors to explain avoidance; it is only necessary to consider the relation between response rates and shock rates. If 
avoidance behavior is considered over an extended period of time, then it becomes apparent that increases in response rates will result in the reduction of shock frequency. Hence, it is argued that only one factor, shock-frequency reduction, is involved in the reinforcement of avoidance responding (e.g. Herrnstein \& Hineline, 1966).

Herrnstein and Hineline (1966) devised a procedure to test the notion that responding could be maintained by shock-frequency reduction. Rats were exposed to two schedules of shock, imposed and alternate, which were unsignaled and usually differed in their rates of shock delivery. Each session began with the imposed schedule in effect. A single lever press switched control of shock delivery to the alternate schedule until the delivery of the next shock. The imposed schedule was then reinstated until the next response. An important feature of this procedure is that lever pressing did not directly cancel or postpone a shock. Lever pressing simply changed the programmed rate of shock delivery. Across conditions, the rates of shock delivery on the imposed and alternate schedules were varied such that accessing the alternate schedule increased, had no effect on, or decreased the level of shock-frequency reduction. In line with Herrnstein and Hineline’s molar interpretation, response rates were directly related to the degree of shock-frequency reduction afforded by accessing the alternate schedule. As the programmed level of shock-frequency reduction increased, so did response rates. Additionally, the rats rarely accessed the alternate schedule when doing so had no effect on, or decreased, the level of shock-frequency reduction.

A potential problem with Herrnstein and Hineline's (1966) procedure is that the alternate schedule is activated with a single lever press and ends with a shock, leaving open the possibility that both responses and shocks can exert stimulus control over responding. As a result, it is not clear if behavior is under the molar control of shock-frequency reduction, or if behavior is under 
the molecular control of responses that initiate a changeover to the alternate schedule and the shocks that end it.

To address the issue, Myers and Perone (1998) conducted three experiments similar to the Herrnstein and Hineline (1966) experiment. Experiment 1 was nearly identical to the Herrnstein and Hineline procedure, the most notable difference being that the rates of shock delivery were lower. Myers and Perone’s results were different. Although lever pressing was maintained, response rates did not increase with reductions in shock frequency. The only consistent pattern in responding was that responses were most likely to occur immediately following shocks, suggesting that shocks were serving a discriminative function.

In Experiment 2, Myers and Perone attempted to reduce the possibility of stimulus control by responses and shocks. The completion of a VI 15-s schedule was required to activate the alternate schedule to reduce the likelihood that changeovers to the alternate schedule occurred after a single response. Additionally, the alternate schedule remained in effect for a time period averaging $30 \mathrm{~s}$ to separate the termination of the alternate schedule from shock. Results from Experiment 2 were similar to those of Experiment 1. Responding was maintained, but there was no direct relation between response rates and shock rates. Instead, as in Experiment 1, responding continued to occur in bursts that immediately followed shocks. In Experiment 2, it is unlikely that shocks delivered on the alternate schedule functioned as discriminative stimuli because the alternate schedule ended after the passage of time rather than after delivery of a shock. The tendency for bursts of post-shock responding suggested that shocks were serving an eliciting function, indicating possible stimulus control.

Experiment 3 attempted to increase sensitivity to the molar contingencies by signaling the imposed and alternate schedules. In conditions where activating the alternate schedule would 
increase shock-frequency reduction, response rates were higher in the imposed schedule than in the alternate schedule. Otherwise, results from Experiment 3 were similar to those of Experiments 1 and 2. Responding was maintained, but response rates did not increase as a function of reductions in shock frequency. Post-shock responding also continued to be high during the alternate schedule. The results from all three experiments suggested that lever pressing, rather than being reinforced by shock-frequency reduction, occurred in bursts that might have been elicited by shocks.

\section{Statement of the Problem}

The conflicting results obtained by Herrnstein and Hineline (1966) and Myers and Perone (1998) make it difficult to determine if responding in these procedures was maintained by shockfrequency reduction or if responding was elicited by shock. This issue might be resolved, in part, by applying a similar procedure to schedules of food delivery, thus eliminating the possibility of shock-elicited responding. Additionally, Myers and Perone only obtained control by reductions in shock frequency when stimuli were correlated with the imposed and alternate schedules (Experiment 3). The addition of stimuli correlated with the schedules introduces a molecular component because an immediate stimulus change occurs when responding activates the alternate schedule. This makes the results of Myers and Perone's Experiment 3 difficult to interpret in terms of sensitivity to the molar contingencies. If, however, subjects are exposed to the contingencies both in the presence and absence of stimuli correlated with the schedules, a cleaner assessment can be made of the sensitivity of behavior to its molar consequences.

The current study addressed the aforementioned issues by applying procedures similar to those used by Myers and Perone (1998) in Experiments 2 and 3 to response-independent, or variable-time (VT), schedules of food delivery. Sessions began with an imposed schedule that 
remained in effect until a VI 15-s schedule was completed on the response lever, whereupon the imposed schedule was suspended and the alternate schedule was activated. The alternate schedule remained in effect for a variable period averaging $30 \mathrm{~s}$, after which the imposed schedule was reinstated. Across conditions, the rate of food delivery arranged by the imposed and alternate schedules was manipulated such that activating the alternate schedule increased, decreased, or had no effect on the rate of food delivery. All rats were exposed to the same absolute changes in the rate of food delivery afforded by activating the alternate schedule, hereafter referred to as food frequency increase (FFI). The way in which FFI was arranged, however, was varied among the rats. This was accomplished by holding particular rates of food delivery constant across conditions (Constancy Variable). Rats were divided into three groups: Constant Overall, Constant Imposed, and Constant Alternate. Across conditions, the overall rate of food delivery was held constant for the Constant Overall group, the imposed schedule rate of food delivery was held constant for the Constant Imposed group, and the alternate schedule rate of food delivery was held constant for the Constant Alternate group. Manipulation of the Constancy Variable provides a test of the molar account because if FFI is the controlling factor, then results should be the same regardless of how FFI is arranged. By contrast, differences among the Constancy Variable groups would suggest that responding was maintained by something other than FFI such as, for example, changes in the imposed or alternate schedule food delivery rates alone.

Another key manipulation was the presence or absence stimuli correlated with the schedules. For half of the rats, the imposed and alternate schedules were signaled. For the other half, no differential stimuli were correlated with the two schedules. Signaling the imposed and alternate schedules adds a molecular feature to the procedure because a switch between the 
schedules results in an immediate stimulus change. Furthermore, the stimulus change is temporally contiguous with the response that activates the alternate schedule. Thus, the true test of the molar account is performance in the absence of signals. If behavior is sensitive to molar contingencies, then responding that activates the alternate schedule should increase when doing so increases the rate of rate of food delivery. This should be the case regardless of whether or not the imposed and alternate schedules are signaled. By contrast, a lack of sensitivity to molar contingencies would be indicated by the occurrence of the aforementioned response patterns in the presence of signals, but not in their absence.

\section{Method}

\section{Subjects}

Twelve experimentally naïve male Sprague-Dawley rats served as subjects. The rats were maintained at $80 \%(+/-2 \%)$ of their free-feeding body weights by food obtained during experimental sessions and, if necessary, supplemental feedings delivered at least a half an hour following the sessions. The rats were housed individually in a temperature-controlled room with a 12:12 hour light/dark cycle.

\section{Apparatus}

Eight identical MED-PC operant test chambers for rats were used. The interior of each chamber was approximately $22 \mathrm{~cm}$ high, $29 \mathrm{~cm}$ long, and $24 \mathrm{~cm}$ deep. The side walls and ceilings were constructed of clear plastic, and the end walls were constructed of stainless steel. The floor consisted of 19 stainless steel rods measuring $0.5 \mathrm{~cm}$ in diameter, and spaced approximately $1.3 \mathrm{~cm}$ apart. General illumination was provided by a houselight containing a No. 1820 bulb situated $17.8 \mathrm{~cm}$ from the floor on the back wall. The front wall contained two retractable levers that were $4.4 \mathrm{~cm}$ wide, $1.3 \mathrm{~cm}$ thick, and protruded $1.9 \mathrm{~cm}$ into the chamber 
when inserted. The levers were situated $5.7 \mathrm{~cm}$ from the middle of the wall $(11.4 \mathrm{~cm}$ apart), and $8 \mathrm{~cm}$ from the floor to the top of the lever. A white cue light (No. 1820 bulb) was situated approximately $5 \mathrm{~cm}$ above each lever. Food pellets (45 mg) were dispensed into a food magazine located on the center of the front wall. The magazine was located approximately 7.6 $\mathrm{cm}$ from the floor, and measured $5 \mathrm{~cm}$ high, $5 \mathrm{~cm}$ wide, and approximately $3.2 \mathrm{~cm}$ deep. Head entries into the magazine were detected by a light source and a photocell located in the magazine. Extraneous sounds were masked by $85 \mathrm{~dB}$ of white noise provided by a speaker located $12 \mathrm{~cm}$ above the floor on the right side of the back wall. Each chamber was enclosed in a ventilated, sound-attenuating outer shell. Experimental events were controlled and recorded by a computer in an adjacent room in conjunction with MED-PC for Windows software and interfacing equipment.

\section{General Procedure}

Experimental sessions were conducted six days per week at approximately the same time each day. To allow the rats time to recover from handling, at least 3 min elapsed between the time the rats were placed in the chamber and the start of the session. During this pre-session delay, the response levers were retracted and the chamber was darkened. When the session was started, the white noise generator was turned on and the chamber was illuminated (the kind of illumination depended on the experimental condition). At the appropriate time, as described below, the right lever was inserted. Each successful lever press produced an audible click. Delivery of a food pellet was accompanied by the offsetting of all lights and the white noise generator. The lights and noise remained off until 2 s elapsed following the rat's head entry into the magazine, after which the noise and appropriate lights were turned on. During the time between the delivery of a pellet and the 2 s following a head entry, all schedules were suspended. 


\section{Preliminary Training}

Magazine Training. During magazine training, the houselight and white noise were turned on, and both response levers were retracted. At the beginning of each session, five pellets were delivered one at a time, at 1-s intervals. Following the rat's initial head entry into the food magazine, another pellet was delivered. Subsequent pellets were delivered according to a differential-reinforcement-of-other-behavior (DRO) schedule. In this procedure, pellets were delivered at the end of regular intervals in which there were no head entries. Head entries during an interval reset the interval. The DRO interval was initially set at $5 \mathrm{~s}$. The DRO interval remained at $5 \mathrm{~s}$ until four consecutive pellets were obtained with a latency of less than $2 \mathrm{~s}$ between the delivery of a pellet and a head entry. Once this criterion was met, the DRO interval was increased in increments of $5 \mathrm{~s}$ until the latency criterion was met on a DRO 20-s schedule. At this point, the DRO schedule became variable, with pellets being delivered at intervals averaging $30 \mathrm{~s}$ with a range of 2 to $99 \mathrm{~s}$. Ten such intervals were derived from Fleshler and Hoffman's (1962) series. Sessions ended once at least 20 pellets were obtained on the variable DRO 30-s schedule and the 2-s latency criterion was met for at least four consecutive pellets. Magazine training ended when the rats completed two consecutive sessions lasting no more than 2 hr each.

Response acquisition. In the current procedure, a switch between two responseindependent schedules of food delivery reinforced lever pressing. Because it was unclear if responding could be acquired under these conditions, lever pressing was reinforced with food. During response acquisition, the houselight and white noise were turned on and the right lever was inserted. In the initial two sessions, each response on the lever was reinforced by the delivery of a food pellet. In each subsequent session, responses were reinforced according to a 
variable-interval (VI) schedule (Fleschler \& Hoffman, 1962). Training on VI schedules began with a VI 5-s schedule, and the value of the VI was raised in steps of $5 \mathrm{~s}$ across the remaining sessions until responding was maintained on a VI 15-s schedule. Rats were typically exposed to each VI value for two sessions. Each session lasted until 50 reinforcers were delivered.

Experimental Procedure

Throughout the experiment, food was delivered according to one of two VT schedules: the imposed schedule and the alternate schedule. The rats were divided into two groups. For the signaled group, the imposed and alternate schedules were differentially signaled by a constantly illuminated houselight on one schedule and a flashing houselight (0.5-s on, 0.5-s off) on the other. The signals were counterbalanced across rats. For the unsignaled group, the houselight remained off and the right cue light was lit during both schedules.

To ensure adequate exposure to the imposed and alternate schedules, a forced-contact period was programmed at the beginning of each session. During the forced-contact period, the levers were retracted and food was delivered according to a compound schedule in which the imposed and alternate schedules were regularly alternated every $2 \mathrm{~min}$. For the unsignaled group, the right cue light remained on during both schedules (i.e., a mixed schedule was in effect). For the signaled group, the houselight was constantly lit during one schedule and flashing during the other (i.e., a multiple schedule). The forced-contact period lasted 8 min, beginning with the imposed schedule and continuing until each schedule component was presented twice.

The session proper began with the insertion of the right lever and, for the signaled group, presentation of the stimulus correlated with the imposed schedule. For the unsignaled group, the right cue light that was on during the forced-contact period remained on during the session 
proper. Food was delivered according to the imposed schedule until a VI 15-s schedule was completed on the lever, at which point the imposed schedule was suspended and the alternate schedule replaced it. To prevent adventitious reinforcement of responding, a 2-s delay was imposed between a response and a scheduled pellet delivery in both the imposed and alternate schedules. The alternate schedule remained in effect for a variable period averaging $30 \mathrm{~s}$ (either $20,25,35$, or 40 s). While the alternate schedule was in effect, responses had no programmed consequence (although they were counted). After the alternate period elapsed, the alternate schedule was suspended and the imposed schedule was reinstated. This continued until 50 pellets were delivered during the session proper.

Across conditions, the food frequency increase (FFI) afforded by accessing the alternate schedule was manipulated. The FFI was derived by subtracting the programmed rate of food delivery (pellets per minute) in the imposed schedule from the programmed rate of food delivery in the alternate schedule. Table 1 shows the order of conditions (defined by FFI). All rats were exposed to FFIs of $3.00,1.50,0.00$, and -1.50 pellets per minute in that order. The final condition was a replication of the 3.00 pellets per minute condition. Also shown in Table 1 are the imposed, alternate, and overall pellet rates, and the VT values for each condition. The listed overall rates are the pellets per minute that could be obtained if the rats spent the maximum possible time on the alternate schedule. The alternate schedule duration averaged $30 \mathrm{~s}$, or twice the time spent in the imposed schedule if the rats promptly completed the VI 15-s schedule required to access the alternate schedule. Hence, the overall rate is calculated using the following equation: $(I+2 \mathrm{~A}) / 3$, where $A$ and $I$ refer to the alternate and imposed pellet rates respectively.

Altering the FFI necessarily results in altering the overall, imposed, and alternate pellet 
Table 1

The order of conditions and the corresponding food frequency increase (FFI), rates of pellet delivery in pellets per minute arranged by the imposed and alternate schedules, parameters of the variable-time (VT) schedules in seconds, and overall pellet rates in pellets per minute for each condition. The number of sessions (Sess) conducted for each rat in each condition is listed in the right portion of the table. Rats are grouped according to their signal condition and the aspect of pellet delivery held constant (Constant Overall, Constant Imposed, and Constant Alternate).

\begin{tabular}{|c|c|c|c|c|c|c|c|c|c|c|c|c|c|}
\hline \multirow[b]{2}{*}{ FFI } & \multicolumn{2}{|c|}{ Imposed } & \multicolumn{2}{|c|}{ Alternate } & \multirow{2}{*}{$\begin{array}{c}\text { Overall } \\
\text { Rate }\end{array}$} & \multicolumn{4}{|c|}{ Signaled } & \multicolumn{4}{|c|}{ Unsignaled } \\
\hline & Rate & $\mathrm{VT}$ & Rate & VT & & Rat & Sess & Rat & Sess & Rat & Sess & Rat & $\overline{\text { Sess }}$ \\
\hline \multicolumn{14}{|c|}{ Constant Overall } \\
\hline 3.00 & 2.00 & 30.00 & 5.00 & 12.00 & 4.00 & $\mathrm{~J} 1$ & 52 & $\mathrm{~J} 4$ & 58 & $\mathrm{~J} 7$ & 50 & $\mathrm{~J} 10$ & 52 \\
\hline 1.50 & 3.00 & 20.00 & 4.50 & 13.33 & 4.00 & $\mathrm{~J} 1$ & 34 & $\mathrm{~J} 4$ & 28 & $\mathrm{~J} 7$ & 36 & $\mathrm{~J} 10$ & 34 \\
\hline 0.00 & 4.00 & 15.00 & 4.00 & 15.00 & 4.00 & $\mathrm{~J} 1$ & 20 & $\mathrm{~J} 4$ & 30 & $\mathrm{~J} 7$ & 20 & $\mathrm{~J} 10$ & 20 \\
\hline-1.50 & 5.00 & 12.00 & 3.50 & 17.14 & 4.00 & $\mathrm{~J} 1$ & 20 & $\mathrm{~J} 4$ & 20 & $\mathrm{~J} 7$ & 30 & $\mathrm{~J} 10$ & 24 \\
\hline $3.00^{\mathrm{a}}$ & 2.00 & 30.00 & 5.00 & 12.00 & 4.00 & $\mathrm{~J} 1$ & 36 & $\mathrm{~J} 4$ & 36 & $\mathrm{~J} 7$ & 50 & $\mathrm{~J} 10$ & 37 \\
\hline \multicolumn{14}{|c|}{ Constant Imposed } \\
\hline 3.00 & 3.00 & 20.00 & 6.00 & 10.00 & 5.00 & $\mathrm{~J} 3$ & 51 & $\mathrm{~J} 6$ & 52 & J9 & 50 & $\mathrm{~J} 12$ & 51 \\
\hline 1.50 & 3.00 & 20.00 & 4.50 & 13.33 & 4.00 & $\mathrm{~J} 3$ & 20 & J6 & 34 & J9 & 34 & $\mathrm{~J} 12$ & 34 \\
\hline 0.00 & 3.00 & 20.00 & 3.00 & 20.00 & 3.00 & $\mathrm{~J} 3$ & 21 & J6 & 21 & J9 & 20 & $\mathrm{~J} 12$ & 20 \\
\hline-1.50 & 3.00 & 20.00 & 1.50 & 40.00 & 2.00 & $\mathrm{~J} 3$ & 22 & J6 & 21 & J9 & 26 & $\mathrm{~J} 12$ & 20 \\
\hline $3.00 \mathrm{a}$ & 3.00 & 20.00 & 6.00 & 10.00 & 5.00 & $\mathrm{~J} 3$ & 37 & $\mathrm{~J} 6$ & 37 & J9 & 36 & $\mathrm{~J} 12$ & 36 \\
\hline \multicolumn{14}{|c|}{ Constant Alternate } \\
\hline 3.00 & 1.00 & 60.00 & 4.00 & 15.00 & 3.00 & $\mathrm{~J} 2$ & 51 & $\mathrm{~J} 5$ & 52 & J8 & 51 & $\mathrm{~J} 14$ & 51 \\
\hline 1.50 & 2.50 & 24.00 & 4.00 & 15.00 & 3.50 & $\mathrm{~J} 2$ & 34 & J5 & 20 & J8 & 36 & $\mathrm{~J} 14$ & 34 \\
\hline 0.00 & 4.00 & 15.00 & 4.00 & 15.00 & 4.00 & $\mathrm{~J} 2$ & 22 & J5 & 24 & J8 & 20 & $\mathrm{~J} 14$ & 20 \\
\hline-1.50 & 5.50 & 10.91 & 4.00 & 15.00 & 4.50 & $\mathrm{~J} 2$ & 27 & J5 & 21 & J8 & 20 & $\mathrm{~J} 14$ & 20 \\
\hline $3.00 \mathrm{a}$ & 1.00 & 60.00 & 4.00 & 15.00 & 3.00 & $\mathrm{~J} 2$ & 36 & J5 & 36 & J8 & 36 & $\mathrm{~J} 14$ & 36 \\
\hline
\end{tabular}

${ }^{\mathrm{a}}$ These conditions were replications of the initial 3.00 condition. 
delivery rates, thus allowing for control of responding by factors other than FFI. This possibility was evaluated by dividing the rats into three groups distinguished in terms of which pellet rates were varied to effect the desired change in the FFI (Constancy Variable). For the Constant Overall group, the imposed and alternate rates were varied but the overall rate was held constant at 4.00 pellets per minute. For the Constant Imposed group, the overall and alternate rates were varied but the imposed rate was held constant at 3.00 pellets per minute. For the Constant Alternate group, the overall and imposed rates varied but the alternate rate was held constant at 4.00 pellets per minute. Table 1 also lists individual rats according to their Signal group (signaled or unsignaled) and their Constancy Variable group. Also listed is the number of sessions conducted for each rat in each condition. In the first condition (3.00 pellets per minute), approximately 50 sessions were conducted for each rat before assessing stability (described below). This was because of uncertainty about whether or not the procedure would maintain responding. Subsequent conditions lasted a minimum of 20 sessions and a maximum of 36 sessions with the exception of the replication of the 3.00 pellets per minute condition. This condition was extended to a minimum of 36 sessions and a maximum of 50 sessions to allow adequate time to recover responding following the -1.50 pellets per minute condition, during which responding was virtually extinguished for most rats. Beginning with the $20^{\text {th }}$ session of each condition $\left(36^{\text {th }}\right.$ session for the replication of the 3.00 pellets per minute condition), stability was assessed by examining the overall response rates over a block of the most recent 12 sessions. If the difference between the means of the first 6 and last 6 sessions of the 12-session block did not differ by more than two responses per minute, and the entire 12-session block was judged free of upward or downward trend by means of visual inspection, the behavior was considered stable and the condition ended. 
Results

Table 2 shows the programmed and obtained FFIs for each rat averaged over the last 12 sessions of each condition. Individual rats are grouped from left to right according to their Constancy Variable group (i.e., Constant Overall, Constant Imposed, and Constant Alternate groups respectively). Obtained FFIs were derived by subtracting the imposed pellet rate from the alternate pellet rate (obtained pellet rates for each rat are shown in the Appendix). Figure 1 is a scatterplot of all rats’ obtained FFIs as a function of programmed FFIs. The dashed diagonal line in the figure depicts perfect correspondence between programmed and obtained FFIs. Most of the points fall close to the diagonal. The departures occur primarily when the programmed FFI was -1.50 pellets per minute, with three points falling well below the diagonal. Table 2 shows that these points represent results of Rats J4 (obtained FFI of -3.54 pellets per min), J10 (4.01), and J8 (-4.31). One other significant departure occurred when the programmed FFI was 0.00 pellets per minute; here Rat J8 had an obtained FFI of -2.39 pellets per min (Table 2).

The solid line in Figure 1 shows the linear regression between programmed and obtained FFIs for all rats. The equation for the line and the proportion of explained variance $\left(r^{2}\right)$ are shown in the upper left of the figure. The slopes, intercepts, and explained variance for each individual rat are listed at the bottom of Table 2. The regression line for all rats (Figure 1) lies close to the diagonal and accounts for a high proportion of the variance $\left(r^{2}=.91\right)$, indicating that changes in the programmed FFIs were mirrored by changes in the obtained FFIs. The linear regression data for individual rats (Table 2) indicates close correspondence between programmed and obtained FFIs. For most rats, slopes were close to 1.0 and intercepts were close to 0.0. Exceptions were Rats J4, J10, and J8, who had slopes of 1.38, 1.56, and 1.71 respectively, and intercepts of $-0.90,-0.86$, and -1.85 respectively. For these rats, the major discrepancies 
Table 2

Programmed and obtained food frequency increases (FFI) in pellets per minute. Rats are grouped according to the aspect of food delivery held constant (Constant Overall, Constant Imposed, and Constant Alternate). The bottom portion of the table lists the slope, intercept, and percentage of explained variance $(r 2)$ of the linear regression equation relating obtained FFI to programmed FFI.

\begin{tabular}{|c|c|c|c|c|c|c|c|c|c|c|c|c|}
\hline \multirow{3}{*}{$\begin{array}{c}\text { Programmed } \\
\text { FFI }\end{array}$} & \multicolumn{12}{|c|}{ Obtained FFI } \\
\hline & \multicolumn{4}{|c|}{ Constant Overall } & \multicolumn{4}{|c|}{ Constant Imposed } & \multicolumn{4}{|c|}{ Constant Alternate } \\
\hline & $\mathrm{J} 1^{\mathrm{a}}$ & $\mathrm{J} 4^{\mathrm{a}}$ & $\mathrm{J} 7$ & $\mathrm{~J} 10$ & $\mathrm{~J}^{\mathrm{a}}$ & $\mathrm{J} 6^{\mathrm{a}}$ & $\mathrm{J} 9$ & $\mathrm{~J} 12$ & $\mathrm{~J} 2^{\mathrm{a}}$ & $\mathrm{J5}^{\mathrm{a}}$ & J8 & $\mathrm{J} 14$ \\
\hline 3.00 & 3.03 & 2.80 & 2.72 & 3.06 & 3.21 & 2.67 & 3.00 & 3.13 & 2.92 & 2.93 & 2.96 & 3.03 \\
\hline 1.50 & 1.71 & 1.49 & 1.53 & 2.18 & 1.80 & 1.76 & 1.63 & 1.68 & 1.48 & 1.55 & 1.47 & 1.47 \\
\hline 0.00 & 0.12 & -0.22 & 0.06 & 0.02 & -0.28 & -0.08 & -0.17 & -0.31 & 0.03 & -0.12 & -2.39 & 0.53 \\
\hline-1.50 & -2.00 & -3.54 & -1.60 & -4.01 & -1.68 & -1.17 & -1.19 & -1.24 & -2.12 & -1.64 & -4.31 & -2.36 \\
\hline $3.00^{\mathrm{b}}$ & 2.87 & 2.99 & 2.96 & 3.04 & 3.15 & 3.11 & 2.51 & 2.85 & 2.21 & 3.01 & 2.87 & 3.08 \\
\hline Slope & 1.11 & 1.38 & 0.96 & 1.56 & 1.12 & 0.89 & 0.96 & 1.01 & 1.11 & 1.02 & 1.71 & 1.14 \\
\hline Intercept & -0.12 & -0.90 & -0.04 & -0.86 & -0.08 & 0.13 & 0.10 & 0.06 & -0.25 & -0.09 & -1.85 & -0.19 \\
\hline$r^{2}$ & 0.99 & 0.95 & 0.99 & 0.92 & 0.99 & 0.98 & 0.99 & 0.98 & 0.99 & 1.00 & 0.97 & 0.95 \\
\hline
\end{tabular}

${ }^{\mathrm{a}}$ These rats are in the signaled group. ${ }^{\mathrm{b}}$ This condition was a replication of the initial 3.00 condition. 


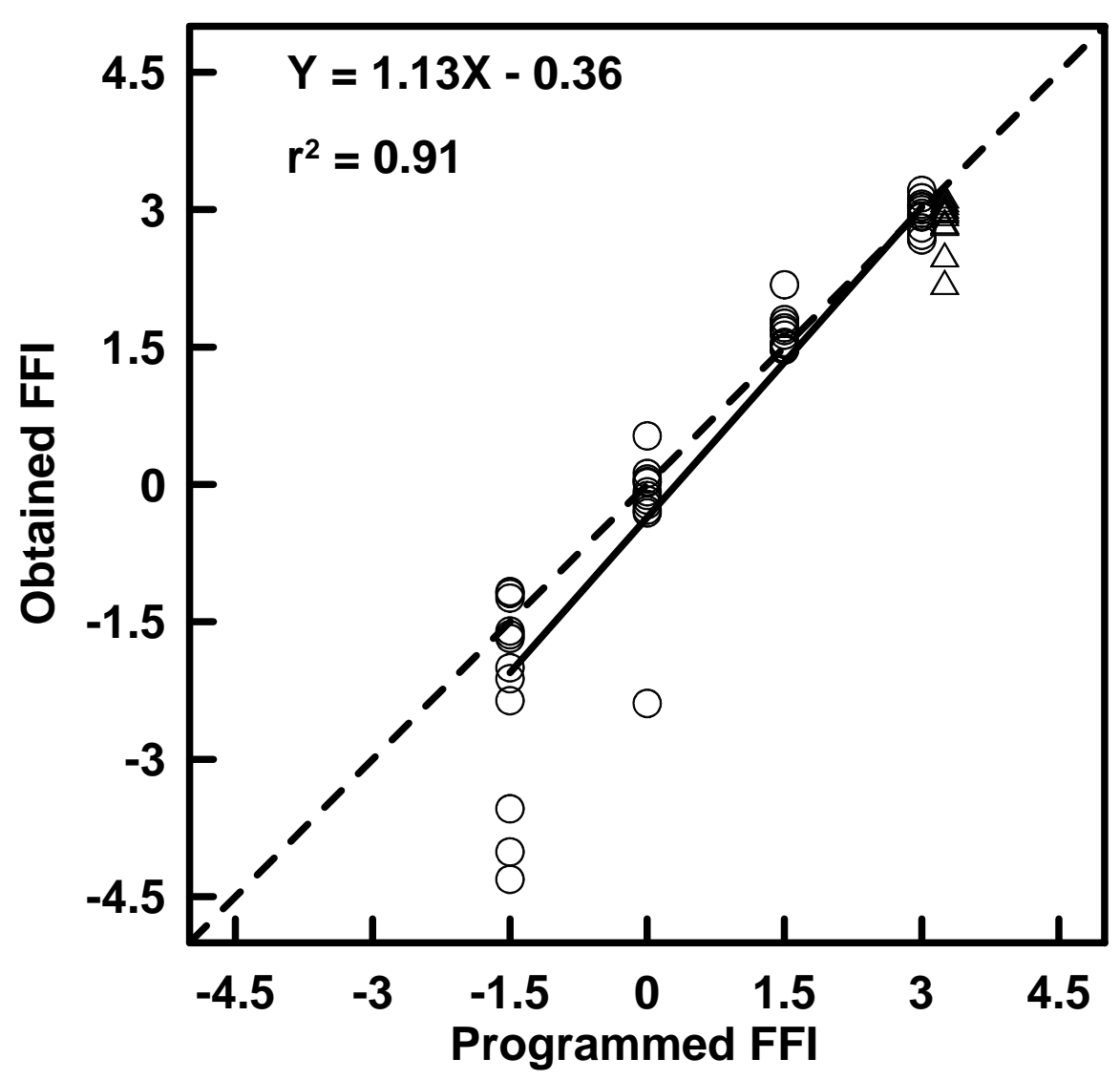

Figure 1. The correlation between obtained and programmed food frequency increases (FFI), based on the last 12 sessions per condition. Open circles depict data from individual rats for $-1.50,0.00,1.50$, and 3.00 conditions. Open triangles depict individual rats' data from the replication of the 3.00 condition. The dashed diagonal line depicts a perfect correlation between obtained and programmed FFIs, and the solid line depicts the regression function. The regression equation and percentage of explained variance $\left(\mathrm{r}^{2}\right)$ are shown in the upper-left corner. 
between obtained and programmed FFIs occurred when the programmed values were -1.50 pellets per minute (all three rats) and 0.00 pellets per minute (J8). There was a high degree of explained variance for all rats with $\mathrm{r}^{2}$ values ranging from .92 to 1.00 .

The results from Table 2 and Figure 1 show close correspondence between programmed and obtained FFIs in all conditions but the -1.50 condition. This is likely a consequence of the failure of the -1.50 condition to maintain much responding, which in turn led to little time spent in the alternate schedule. This issue is addressed in Table 3. The left portion of Table 3 shows the means (and standard deviations) of the time spent in the alternate schedule for each rat for each condition, and the right shows the proportion of time spent in the alternate schedule. Individual rats are grouped from top to bottom according to the Constancy Variable (Constant Overall, Constant Imposed, and Constant Alternate groups respectively). For most rats, the mean time and the proportion of the session spent in the alternate schedule decreased as the FFI decreased. At a programmed FFI of -1.50 pellets per minute, the time was notably lower for Rats J4 (0.38 min), J10 (0.41 min), J8 (0.11 min) and J14 (0.53 min), yielding proportions of .04, $.04, .01$, and .06 respectively. A possible consequence of minimal time spent in the alternate schedule is an obtained alternate pellet rate that is lower than the programmed rate, which in turn can lead to a deflated obtained FFI. At a programmed FFI of -1.50 pellets per minute, three of the four rats that spent minimal time in the alternate schedule (Rats J4, J10, and J8) had obtained FFIs that substantially departed from programmed FFIs (see Table 2). It is worth noting that Rats J4, J10, and J8 also had low obtained alternate pellet rates in the -1.50 condition (see the Appendix).

Taken together, the results from Figure 1 and Tables 2 and 3 indicate that the rats adequately contacted changes in the programmed FFIs. Discrepancies in the -1.50 condition are 
Table 3

Mean session time in minutes (standard deviations in parentheses) and the proportions of the session spent in the alternate schedule. Rats are grouped according to the aspect of pellet delivery held constant (Constant Overall, Constant Imposed, and Constant Alternate).

\begin{tabular}{|c|c|c|c|c|c|c|c|c|}
\hline \multicolumn{9}{|c|}{ Constant Overall } \\
\hline \multirow[b]{2}{*}{ FFI } & \multicolumn{4}{|c|}{ Time in Alternate } & \multicolumn{4}{|c|}{$\begin{array}{c}\text { Proportion of } \\
\text { Session in Alternate }\end{array}$} \\
\hline & $\mathrm{J} 1^{\mathrm{a}}$ & $\mathrm{J} 4^{\mathrm{a}}$ & J7 & $\mathrm{J} 10$ & $\mathrm{~J} 1^{\mathrm{a}}$ & $\mathrm{J} 4^{\mathrm{a}}$ & $\mathrm{J} 7$ & $\mathrm{~J} 10$ \\
\hline 3.00 & $7.24(0.41)$ & $7.59(0.29)$ & $6.82(0.59)$ & $5.39(0.79)$ & .52 & .59 & .46 & .34 \\
\hline 1.50 & $5.48(0.68)$ & $4.61(1.49)$ & $7.23(0.44)$ & $3.06(1.48)$ & .40 & .32 & .56 & .21 \\
\hline 0.00 & $3.95(0.87)$ & 3.15 (1.29) & $6.03(0.57)$ & $1.91(0.96)$ & .32 & .23 & .47 & .16 \\
\hline-1.50 & $1.03(0.62)$ & $0.38(0.43)$ & $4.51(0.72)$ & $0.41(0.56)$ & .10 & .04 & .41 & .04 \\
\hline $3.00^{\mathrm{b}}$ & $6.57(0.54)$ & $7.08(0.52)$ & $7.30(0.54)$ & $6.44(0.28)$ & .44 & .51 & .51 & .44 \\
\hline \multicolumn{9}{|c|}{ Constant Imposed } \\
\hline & \multicolumn{4}{|c|}{ Time Spent in Alternate } & \multicolumn{4}{|c|}{$\begin{array}{c}\text { Proportion of } \\
\text { Session in Alternate }\end{array}$} \\
\hline FFI & $\mathrm{J3}^{\mathrm{a}}$ & $\mathrm{J}^{\mathrm{a}}$ & J9 & $\mathrm{J} 12$ & $\mathrm{J3}^{\mathrm{a}}$ & $\mathrm{J}^{\mathrm{a}}$ & J9 & $\mathrm{J} 12$ \\
\hline 3.00 & $5.00(0.77)$ & $2.69(1.64)$ & $4.91(0.76)$ & 3.84 (1.07) & .41 & .19 & .40 & .29 \\
\hline 1.50 & $5.83(0.63)$ & $5.92(0.56)$ & $4.42(1.15)$ & $3.84(0.97)$ & .42 & .43 & .31 & .27 \\
\hline 0.00 & $4.22(1.30)$ & $5.11(1.02)$ & $5.08(0.88)$ & $2.62(0.89)$ & .25 & .29 & .30 & .16 \\
\hline-1.50 & $2.68(0.93)$ & $3.83(0.83)$ & $4.89(1.02)$ & $2.43(0.73)$ & .15 & .21 & .26 & .14 \\
\hline $3.00^{\mathrm{b}}$ & $3.34(0.86)$ & $4.57(0.62)$ & $3.08(0.77)$ & $1.11(0.41)$ & .25 & .36 & .22 & .07 \\
\hline \multicolumn{9}{|c|}{ Constant Alternate } \\
\hline & \multicolumn{4}{|c|}{ Time Spent in Alternate } & \multicolumn{4}{|c|}{$\begin{array}{l}\text { Proportion of } \\
\text { ssion in Alternate }\end{array}$} \\
\hline FFI & $\mathrm{J}^{\mathrm{a}}$ & $\mathrm{J}^{\mathrm{a}}$ & J8 & J14 & $\mathrm{J} 2^{\mathrm{a}}$ & $\mathrm{J}^{\mathrm{a}}$ & J8 & $\mathrm{J} 14$ \\
\hline 3.00 & $10.29(0.89)$ & $10.64(0.44)$ & $10.08(0.84)$ & $8.98(1.15)$ & .56 & .59 & .54 & .42 \\
\hline 1.50 & $8.05(0.43)$ & $8.48(0.78)$ & $6.29(1.66)$ & 3.68 (1.55) & .52 & .56 & .39 & .20 \\
\hline 0.00 & $5.25(0.66)$ & $4.49(0.73)$ & $1.05(1.13)$ & $1.68(0.81)$ & .43 & .35 & .08 & .14 \\
\hline-1.50 & $1.52(0.99)$ & $1.52(0.74)$ & $0.11(0.25)$ & $0.53(0.42)$ & .16 & .16 & .01 & .06 \\
\hline $3.00^{\mathrm{b}}$ & $10.46(0.59)$ & $10.50(0.65)$ & $5.99(2.45)$ & $9.75(0.71)$ & .56 & .56 & .19 & .48 \\
\hline
\end{tabular}

${ }^{\mathrm{a}}$ These rats are in the signaled group. ${ }^{\mathrm{b}}$ These conditions were replications of the initial 3.00 condition. 
attributable to the performance of three rats (Rats J4, J10, and J8), whose minimal contact with the alternate schedule may have deflated their FFIs. The results also justify, for purposes of simplicity, the use of programmed FFIs for subsequent analyses.

The main purpose of the current study was to assess sensitivity to changes in the rate of food delivery. Only responding in the imposed schedule could change the rate of food delivery (by producing the alternate schedule); responding during the alternate schedule had no programmed consequences. Sensitivity, then, would be indicated by changes in imposedschedule response rates that are directly related to changes in FFIs. Therefore, subsequent analyses emphasize responding during the imposed schedule.

A potential influence on sensitivity of responding to changing rates of food delivery is the degree to which the changes are discriminated. This issue is addressed in Figure 2, which shows relative response rates on the imposed schedule as a function of FFI. In this and all subsequent figures showing results from individual rats, data points represent the means of the 12 stable sessions for each condition and error bars extend one standard deviation above and below the mean. The left column of each figure shows results from the signaled group, and the right from the unsignaled group. The Constancy Variable (Constant Overall, Constant Imposed, and Constant Alternate) is listed within each individual panel. Open circles depict replications of the 3.00 condition.

Relative response rates were derived by dividing response rates in the imposed schedule by the sum of rates in the imposed and alternate schedule. With this measure, relative rates that differ from .5 (represented by a dashed line in Figure 2) indicate discrimination of the change from the imposed schedule to the alternate. A limitation of this analysis is the sensitivity of relative response rates to extremely low absolute response rates. For example, if a rat made two 


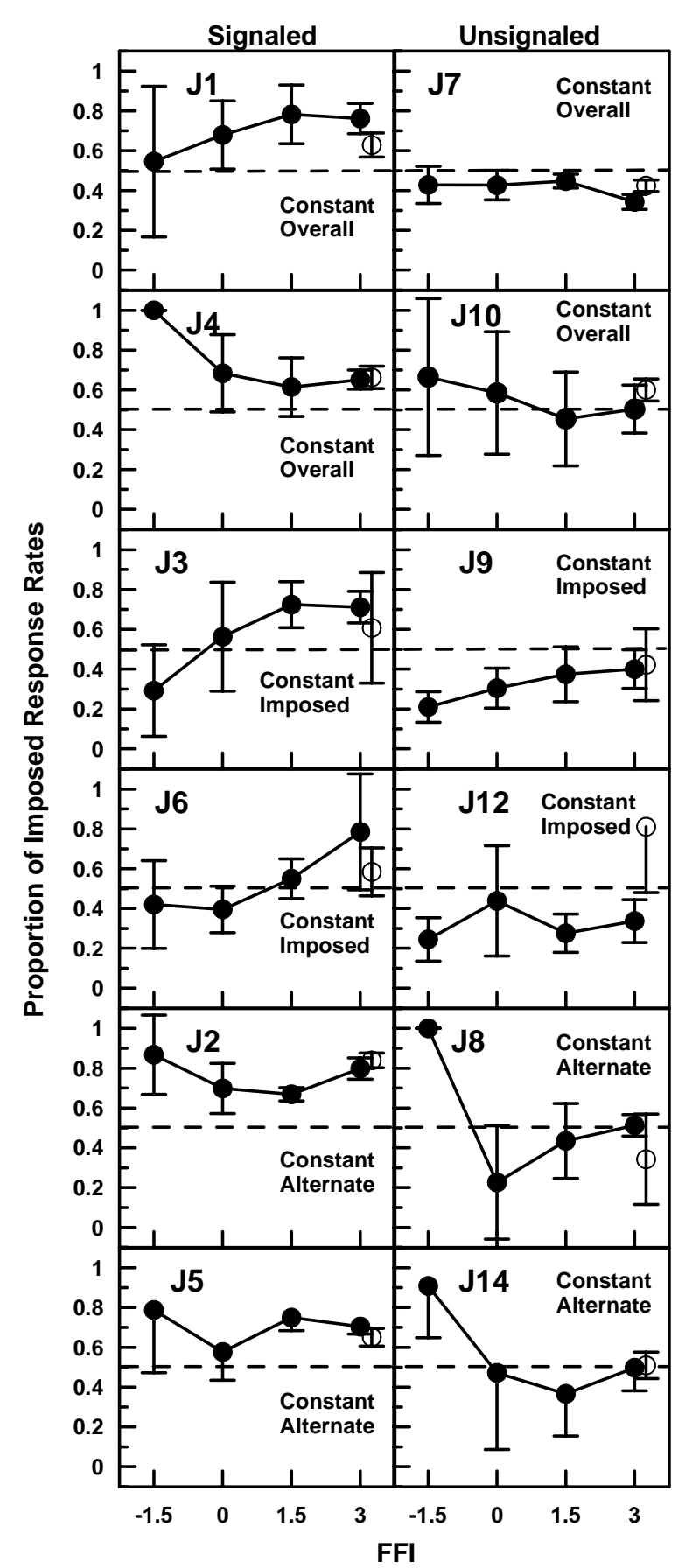

Figure 2. Relative response rates as a function of food frequency increase (FFI). Relative response rates are response rates on the imposed schedule as a proportion of the combined rates on the imposed and alternate schedules. Filled circles depict means from the $-1.50,0.00,1.50$, and 3.00 conditions. Open circles depict means from the replication of the 3.00 conditions (offset to the right). Error bars extend one standard deviation above and below the means. The dashed horizontal line depicts equal responding in the imposed and alternate schedules. The left and right panels include rats in the signaled and unsignaled groups respectively. The Constancy Variable (Constant Overall, Constant Imposed, and Constant Alternate) for each rat is listed within the panels. Data are from the last 12 sessions per condition. 
responses throughout the entire session, and both responses occurred during the imposed schedule, the resulting relative response rates would be 1.0. This would imply perfect discrimination of the changes between the schedules. Instead, such low absolute rates would be more indicative of unsystematic behavior undergoing extinction. Considering this, and the fact that many of the rats' response rates were extremely low at FFIs of -1.50 and 0.00 pellets per minute (discussed below), the analyses of relative response rates will focus on the conditions that reliably sustained responding, that is, the conditions with FFIs of 1.50 and 3.00 pellets per min.

Figure 2 shows that rats in the signaled group generally discriminated the imposed and alternate schedules, as indicated by relative response rates above the dashed line. For the unsignaled group, there was less discrimination of the schedules as indicated by data points falling closer to the dashed line. These results indicate that the signals enhanced the discriminability of the imposed and alternate schedules. This was confirmed by a repeatedmeasures analysis of variance (ANOVA) with Signal (signaled and unsignaled) and the Constancy Variable (Constant Overall, Constant Imposed, and Constant Alternate) as betweengroup factors and FFI as the within-group factor. Only a significant effect of Signal was revealed by the ANOVA, $F(1,6)=84.92, p<.001$. The mean relative rate of the signaled group was .71 (standard error $=.02)$ versus a mean of .41 (.01) for the unsignaled group.

Figure 3 shows response rates on the imposed schedule as a function of FFI for each rat. In general, response rates were modest in all conditions, with only Rat J5 exceeding 10 responses per minute. Five of six rats in the signaled group showed an increase in response rates as the FFI increased. The exception was J6, who showed an increase in response rates between the -1.50 and 1.50 conditions followed by a decrease in the 3.00 condition. Rats J4 and J5 showed increases in response rates with increases in FFI, but response rates in the replication of the 3.00 


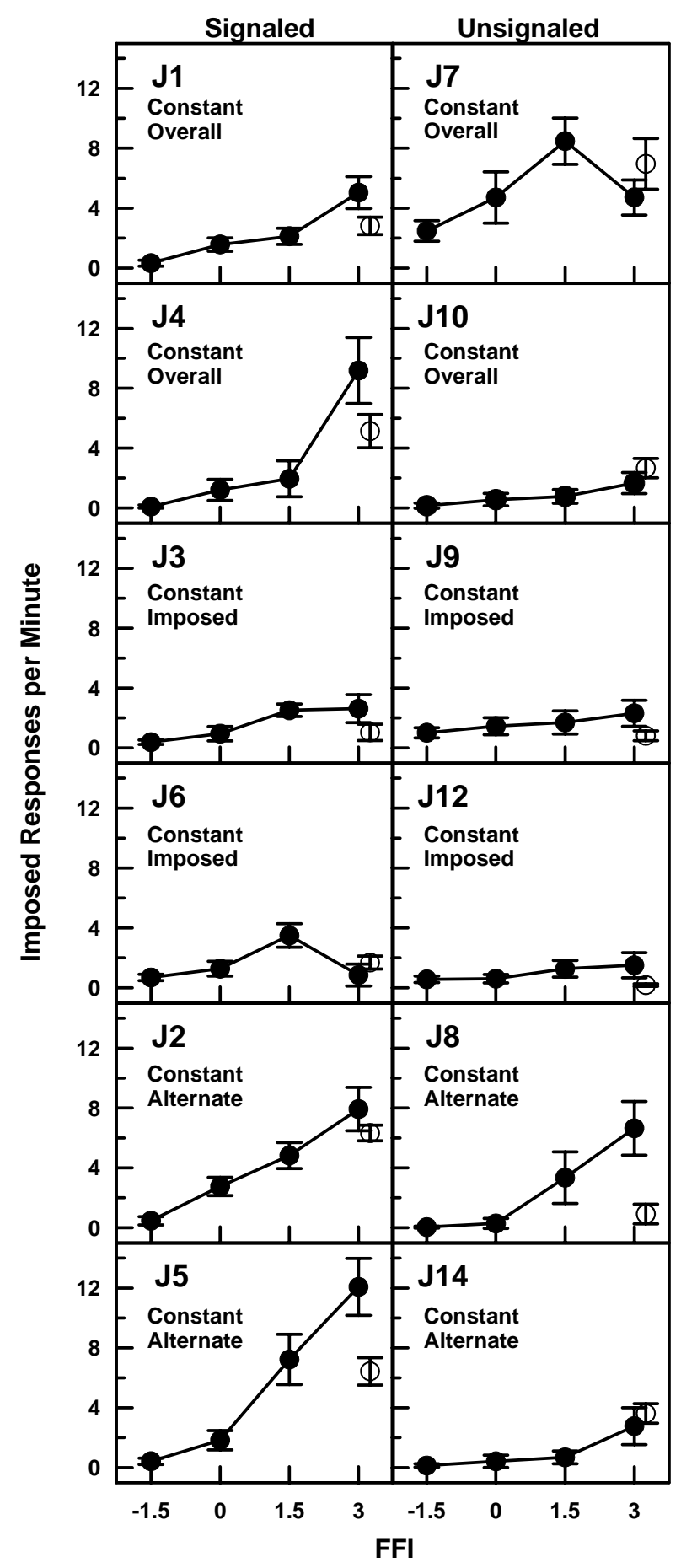

Figure 3. Responses per minute on the imposed schedule as a function of the food frequency increase (FFI) afforded by the switch from the imposed to the alternate schedule. Filled circles depict means from the $-1.50,0.00,1.50$, and 3.00 conditions. Open circles depict means from the replication of the 3.00 conditions (offset to the right). Error bars extend one standard deviation above and below the means. The left and right panels include rats in the signaled and unsignaled groups respectively. The Constancy Variable (Constant Overall, Constant Imposed, and Constant Alternate) for each rat is listed within the panels. Data are from the last 12 sessions per condition. 
condition were lower than in the initial 3.00 condition. The effect of FFI was less clear for rats in the unsignaled group. Although Rat J8 showed an increase in response rates as the FFI increased, response rates in the replication of the 3.00 condition were substantially lower than in the initial 3.00 condition. Rat J7 showed an increase in response rates between the -1.50 and 1.50 conditions followed by a decrease in the 3.00 condition. Rats J14 and J10 showed slightly elevated responding in both the initial 3.00 condition and the replication of the 3.00 condition. For Rats J9 and J12, response rates were very low, and showed minimal changes across conditions.

Figure 3 also shows differences among the rats as a function of the Constancy Variable. For the Constant Overall group, Rats J1, J4, and J7 show changes in response rates across conditions. The same is true of Rats J2, J5, and J8 in the Constant Alternate group. Although Rat J6 shows slightly elevated responding in the 1.50 condition, in the Constant Imposed group there are minimal changes in response rates across conditions. Thus, the effect of the Constancy variable is evident in the increased responding in the Constant Overall and Constant Alternate groups, and the absence of changes in responding in the Constant Imposed group.

Several analyses of the grouped data were conducted using a repeated measures analysis of variance (ANOVA) The between-group factors were Signal (signaled and unsignaled) and the Constancy Variable (Constant Overall, Constant Imposed, and Constant Alternate). The withinsubject factor was FFI (-1.50, 0.00, 1.50, and 3.00 pellets per minute). For each significant effect, pairwise comparisons were conducted using a Bonferroni adjustment. Replications of the 3.00 condition were not included in the analyses of grouped data.

A chief concern with the repeated measures ANOVA is the assumption of sphericity, which is related to assumptions about the homogeneity of variances within treatments. 
Violations of the assumption of sphericity render interpretations of the $F$ ratio unclear (Keppel, 1991). According to Keppel, it is safe to assume that repeated-measures designs violate the assumption of sphericity and, as such, require correction. For the current analysis, the Greenhouse-Geisser correction was used. Because this correction tends to drop the alpha level below .05 by negatively biasing the $F$ ratio (Keppel), both corrected and uncorrected statistics are reported. Plots of significant effects are shown in Figure 4, all of which show mean response rates in the imposed schedule (+/- standard errors) as a function of FFI.

The ANOVA revealed a significant effect of FFI, $F(3,18)=23.45$, uncorrected $p<.001$, corrected $p<.001$. As shown in the top panel of Figure 4, response rates in the imposed schedule increased as the FFI increased. An analysis of the simple main effects of FFI showed significant differences between FFIs of -1.50 versus $0.00(p<.05), 1.50(p<.01)$, and 3.00 pellets per minute $(p<.05)$. There were also significant differences between FFIs of 0.00 versus FFIs 1.50 and 3.00 pellets per minute (both $p s<.05$ ).

The ANOVA revealed a significant interaction between FFI and Signal, $F(3,18)=3.57$, uncorrected $p=.035$, corrected $p=.065$. The middle panel of Figure 4 shows that response rates increased as a function of FFI in the signaled group. An analysis of the simple main effects of FFI for the signaled group showed significant differences between FFIs of -1.5 versus 0.00 , 1.50, and 3.00 pellets per minute, and between FFIs of 0.00 versus 3.00 pellets per minute (all ps $<$.05). There were no significant simple main effects of FFI in the unsignaled group. On average, then, responding on the imposed schedule was sensitive to FFI when the switch between the imposed and alternate schedules was signaled, but responding was insensitive in the absence of signals.

Finally, the ANOVA revealed a significant interaction between FFI and the Constancy 


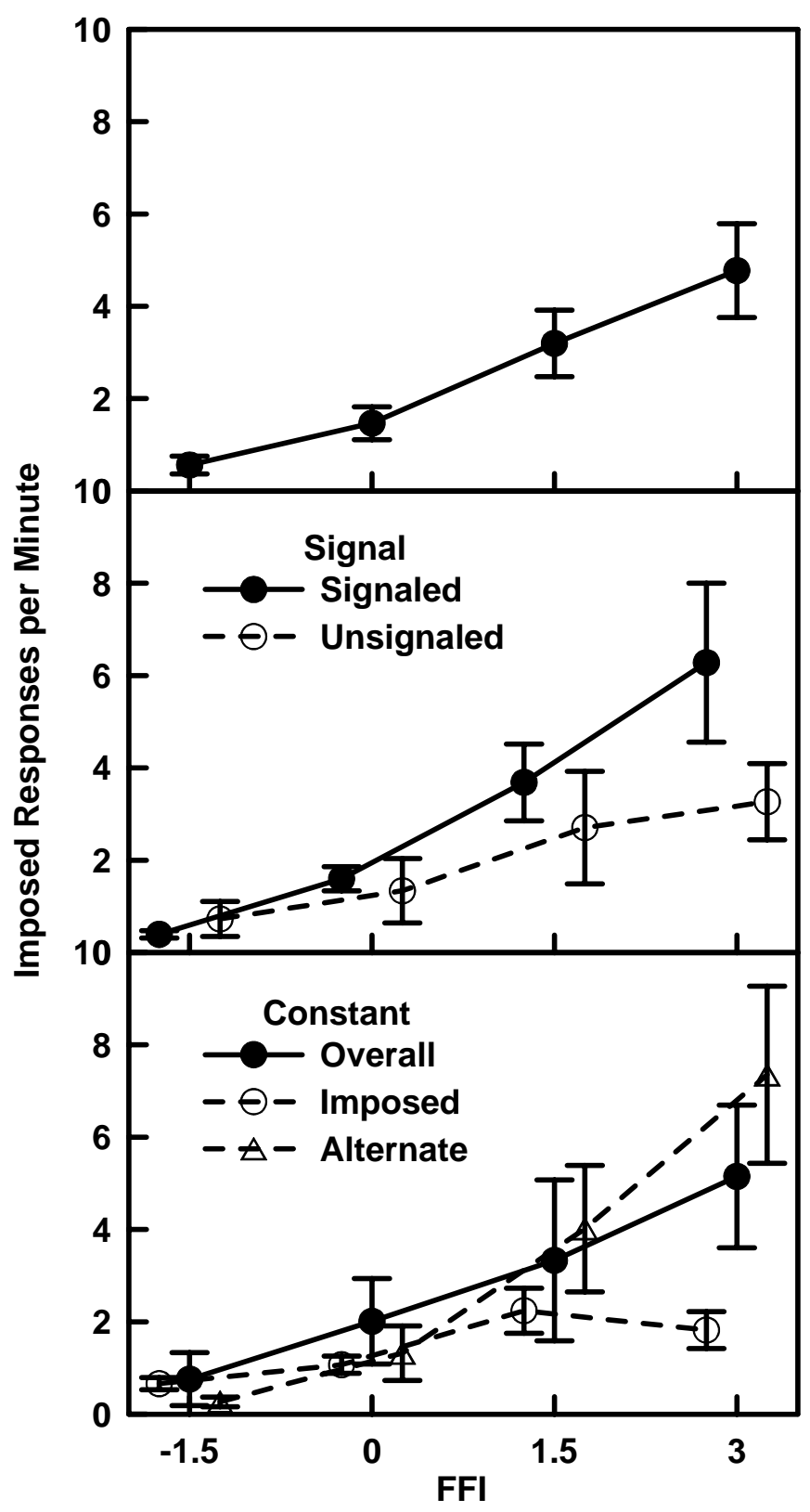

Figure 4. Responses per minute on the imposed schedule as a function of the food frequency increase (FFI) afforded by the switch from the imposed to the alternate schedule. Data points depict group means and error bars extend one standard error above and below the means. Top: results for all 12 rats. Middle: results for the signaled and unsignaled groups. Bottom: results for the Constant Overall, Constant Imposed, and Constant Alternate groups. Data are from the last 12 sessions of each condition. 
Variable $F(6,18)=4.00$, uncorrected $p=.010$, corrected $p=.031$. The lower panel of Figure 4 shows an increase in response rates with increases in FFIs for the Constant Overall and Constant Alternate groups, although there was a large amount of variability in the data across most conditions. By contrast, the Constant Imposed group shows little effect of FFI. An analysis of simple main effects of FFI for the Constant Overall group shows a significant difference between FFIs of -1.50 versus 0.00 pellets per minute $(p<.05)$. For the Constant Alternate group, there were significant differences between FFIs of -1.50 versus $1.50(p<.05)$ and 3.00 pellets per minute $(p<.01)$, and between FFIs of 0.00 versus 3.00 pellets per minute $(p<.05)$. There were no significant simple main effects of FFI for the Constant Imposed group.

Taken together, the analysis of both individual and group data suggest that changes in FFIs are responsible for changes in response rates, but the effect of FFI depends on the presence of stimuli and the particular method of programming the FFI. Response rates were typically higher and showed greater changes as a function of FFI in the presence of signals. The ANOVA showed an effect of FFI in the signaled group, but there were no reliable differences in response rates at any level of FFI in the unsignaled group. The analysis of individual data indicates some effects of FFI for Rats J7, J10, and J14 in the unsignaled group, but the effects were not nearly as robust as the effects seen in the signaled group.

The Constancy variable also had an effect on responding. This is particularly evident when comparing the Constant Imposed and Constant Alternate groups. Statistical analyses revealed several simple effects of FFI in the Constant Alternate group, but no simple effects in the Constant Imposed group. The analysis of individual data is consistent with these results, revealing that response rates were low for both signaled and unsignaled rats in the Constant Imposed group. By contrast, effects of FFI were seen in rats in the signaled (Rats J2 and J5) and 
unsignaled (Rat J14) groups in the Constant Alternate group. Both individual and group analyses also revealed effects of FFI in the Constant Overall group.

The previous analyses focused on changes in response rates as a function of changes in FFI. Control by FFI is conceptualized as a joint function of imposed and alternate pellet rates. It is possible, however, that changes in response rates could be a sole function of changes in the imposed or alternate pellet rates, or the overall pellet rates. This issue is addressed in Figures 5 through 7.

Figure 5 shows data for the Constant Overall Group. For this group, imposed pellet rates decreased as alternate pellet rates increased, whereas overall pellet rates were held constant (see Table 1). The top panel shows response rates on the imposed schedule as a function of imposed pellet rates. For Rats J1 and J4, response rates decreased as imposed pellet rates increased. Rat $\mathrm{J} 7$ shows an increase in response rates between 2 and 3 pellets per minute, and a decrease in response rates between 3 and 5 pellets per minute. Rat J10 shows modest changes as a function of pellet rate, with the highest response rates at the lowest pellet rate ( 2 pellets per minute). The middle panel shows response rates on the imposed schedule as a function of alternate pellet rates. Rats J1, J4, and to a lesser extent, J10 show increased response rates as alternate pellet rates increased. Response rates for Rat J7 increased between 3.5 and 4.5 pellets per minute, and then decrease between 4.5 and 5.0 pellets per minute. The bottom panel shows response rates on the imposed schedule as a function of overall pellet rates. Despite the fact that overall rates were held constant for this group, variability in response rates is evident in all rats. These results indicate that response rates were a function of something other than overall pellet rates. The controlling factors, however, are not clear. There is a tendency to see decreases in response rates with increases in imposed pellet rates, and increases in response rates with increases in alternate 

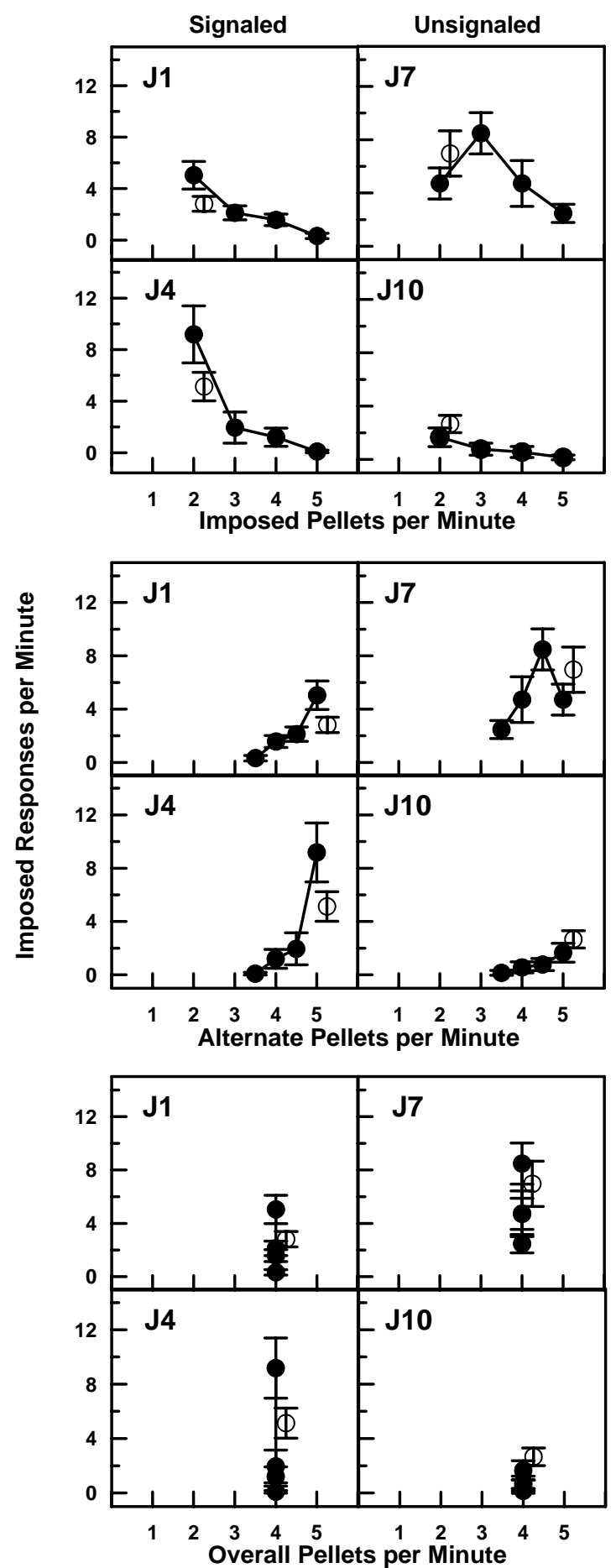

Figure 5. Responses per minute on the imposed schedule as a function of imposed pellets per minute (top), alternate pellets per minute (middle), and overall pellets per minute (bottom) for the Constant Overall Group. Filled circles depict means from the $-1.50,0.00,1.50$, and 3.00 conditions. Open circles depict means from the replication of the 3.00 conditions (offset to the right). Error bars extend one standard deviation above and below the means. The left and right panels include rats in the signaled and unsignaled groups respectively. Data are from the last 12 sessions per condition. 
pellet rates, but the effects of imposed and alternate pellet rates are confounded by the fact that they moved in opposite directions across conditions.

Figure 6 shows data for the Constant Imposed Group. For this group, imposed pellet rates were held constant, whereas alternate and overall pellet rates were raised simultaneously (see Table 1). The top panel shows response rates on the imposed schedule as a function of imposed pellet rates. For all four rats, little variability is seen in the data. While this might suggest exclusive control by the imposed pellet rate, it could also be an artifact of the generally low response rates across conditions for all four rats. The middle panel shows response rates on the imposed schedule as a function of alternate pellet rates and the bottom panel shows response rates as a function of overall pellet rates. Functions in both sets of panels are nearly identical. Slight increases in response rates as a function of both alternate and overall pellet rates are evident in all four rats. Because the procedures confound the variables, it is difficult to determine if either or both alternate and overall pellet rates have an impact on the behavior.

Figure 7 shows data for the Constant Alternate Group. For this group, imposed pellet rates were raised while alternate pellet rates were held constant with commensurate increases in overall pellet rates (see Table 1). The top panel shows response rates on the imposed schedule as a function of imposed pellet rates. For Rats J2, J5, and J8, response rates decreased as imposed pellet rates were raised. Rat J14 shows a decrease in response rates between 1.0 and 2.5 pellets per minute, and little change thereafter. The middle panel shows response rates as a function of alternate schedule pellet rates. Despite the fact that alternate pellet rates were held constant for this group, variability in response rates is evident for Rats J2, J5, J8, and to a lesser extent, J14. The bottom panel shows response rates as a function of overall pellet rates. For all rats, response rates decrease as overall pellet rates increase (although the decrease was minimal for Rat J14). 

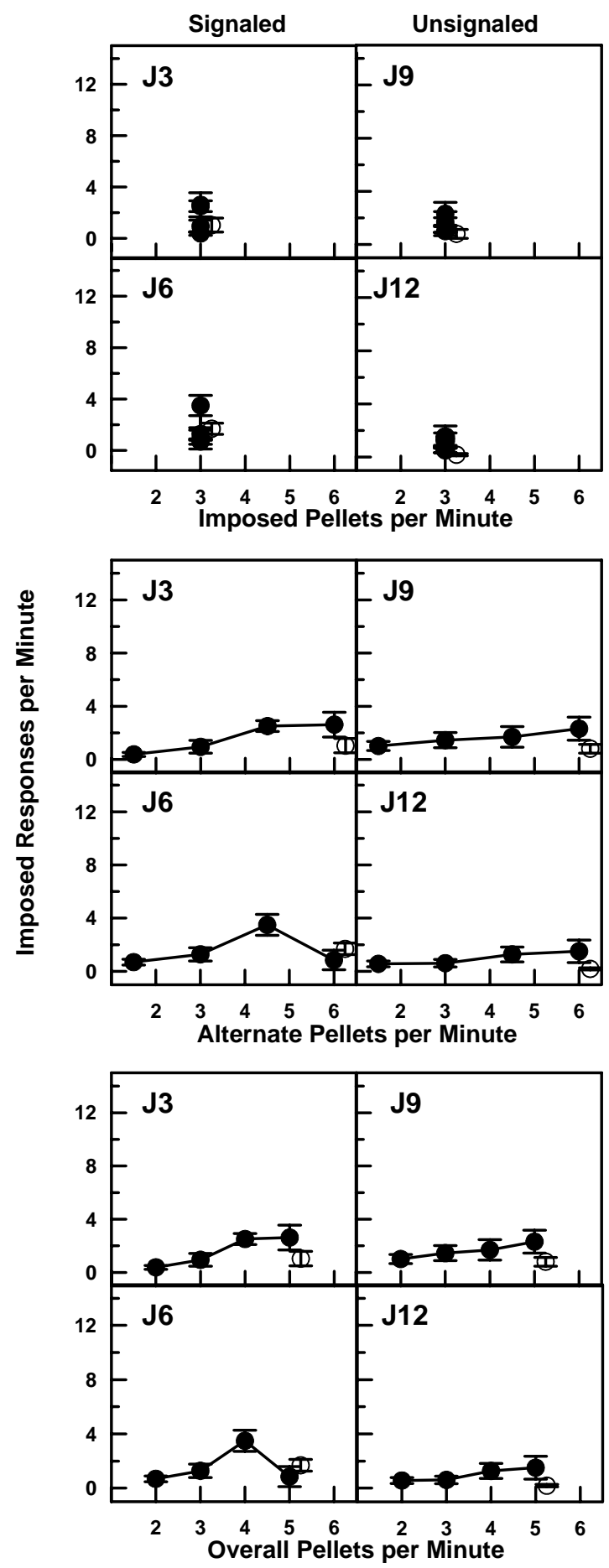

Figure 6. Responses per minute on the imposed schedule as a function of imposed pellets per minute (top), alternate pellets per minute (middle), and overall pellets per minute (bottom) for the Constant Imposed Group. Other details are as in Figure 5. 

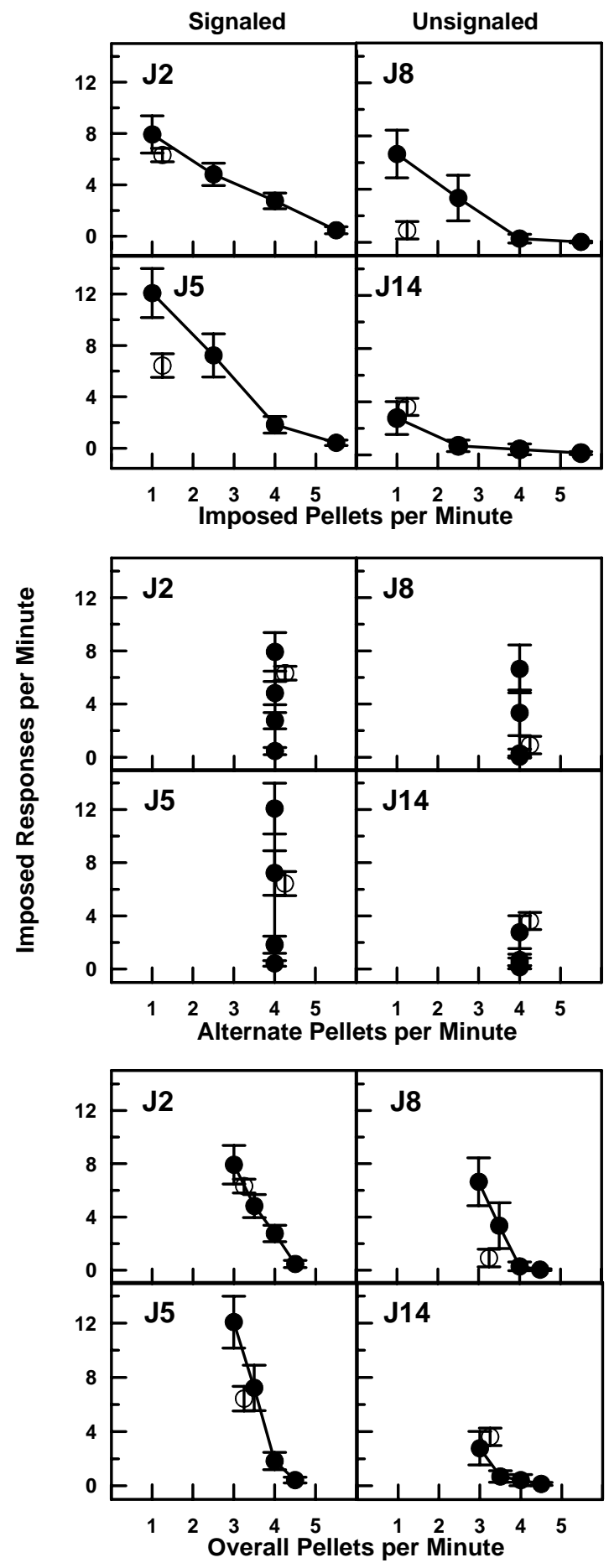

Figure 7. Responses per minute on the imposed schedule as a function of imposed pellets per minute (top), alternate pellets per minute (middle), and overall pellets per minute (bottom) for the Constant Alternate Group. Other details are as in Figure 5. 
The variability in response rates as a function of alternate pellet rates (which were held constant for this group) indicates that something other than alternate pellet rates controlled responding. The contributions of imposed and overall rates are difficult to determine, however, because the two variables are confounded.

Taken together, results from Figures 5, 6, and 7 indicate that changes in responding cannot be attributed to any single aspect of the scheduling of pellet delivery. Instead, responding seems to be a combined function of, at the very least, imposed and alternate pellet rates. The degree to which these variables controlled behavior is difficult to determine because imposed an alternate pellet rates are confounded in the Constant Overall group, response rates are too low to make clear assessments of imposed pellet rates in the Constant Imposed group, and imposed and overall pellet are confounded in the Constant Alternate Group.

Because food was delivered according to response-independent schedules, the possibility exists that responding was maintained by adventitious reinforcement. If this were the case, response rates on the imposed and alternate schedules should increase as rates of pellet delivery on those schedules are raised. To the contrary, response rates on the imposed schedule decreased as imposed pellet rates increased (see Figures 5 and 7). Furthermore, a 2-s delay between a response and a scheduled pellet delivery was employed to reduce the likelihood of such an occurrence. Nonetheless response rates in the alternate schedule should be examined to rule out such a possibility.

Figure 8 shows response rates on the alternate schedule as a function of alternate pellet rates. For the Constant Overall group, Rats J4, J7, and J10 show increases in response rates as a function of alternate pellet rates. Despite these results, adventitious reinforcement seems unlikely considering that these rats' response rates on the imposed schedule decreased as 


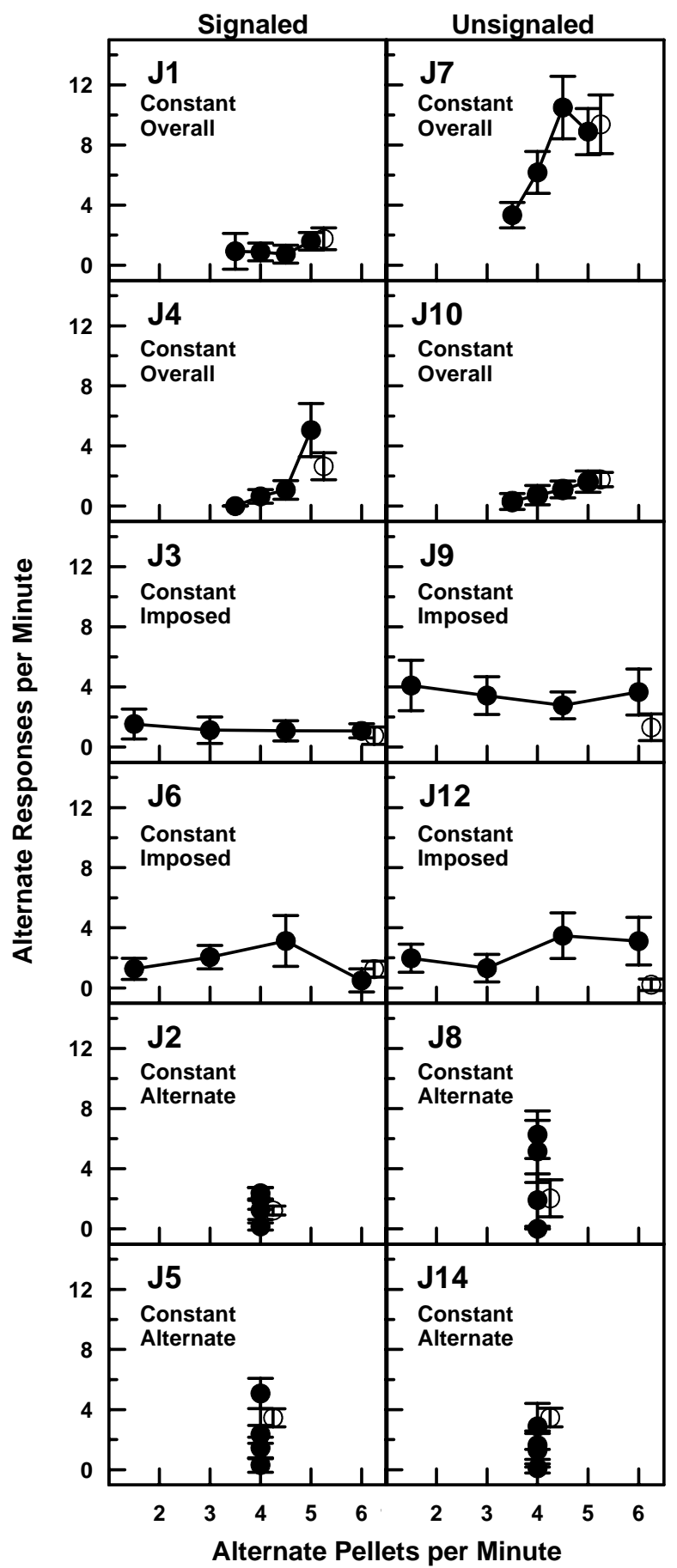

Figure 8. Responses per minute on the alternate schedule as a function of alternate pellets per minute. Other details are as in Figure 3. 
imposed pellet rates were raised (Figure 5). For the Constant Imposed group, there is little effect of alternate pellet on alternate response rates. For the Constant Alternate group, there is enough variability in response rates to suggest that something other than alternate pellet rates were controlling alternate response rates. Taken together, results from Figures 5, 7, and 8 provide little evidence of adventitious reinforcement.

A final question is why, despite being exposed to the same FFIs as the other groups, were response rates so low and undifferentiated in the Constant Imposed group? This result may be explained by noting that while all rats were exposed to the same absolute FFIs (alternate imposed pellet rates), the relative FFIs (alternate / imposed) differed among the Constancy Variable groups. Table 4 shows that although relative FFIs were similar across the groups at programmed FFIs of $-1.50,0.00$, and 1.50 pellets per minute, a wider range of relative FFIs occured at a programmed FFI of 3.00 pellets per minute. The Constant Overall, Constant Imposed, and Constant Alternate groups were exposed to relative FFIs of 2.50, 2.00, and 4.00 pellets per minute respectively. Figure 9 shows response rates on the imposed schedule as a function of relative FFI. As indicated by the close grouping of data points, the Constant Imposed group was exposed to a limited range of relative FFI. Rats that showed higher response rates did so at relative FFIs that were near or exceeded the highest relative FFI of the Constant Imposed group. This is particularly true of the Constant Alternate group, whose largest relative FFI was twice that of the Constant Imposed group. Hence, for the Constant Imposed group, minimal differences in response rates across conditions may have been a result of minimal differences in the relative FFI across conditions. Results from Figure 9 imply that changes in response rates may be more a function of changes in relative FFI than absolute FFI. 
Table 4

Programmed food frequency increases (FFI, alternate pellet rate - imposed pellet rate) in pellets per minute and relative FFI (alternate pellet rate / imposed pellet rate) for each Constancy Variable group (Constant Overall, Constant Imposed, and Constant Alternate)

\begin{tabular}{cccc}
\hline & \multicolumn{3}{c}{ Relative FFI per Group } \\
\cline { 2 - 4 } $\begin{array}{c}\text { Programmed } \\
\text { FFI }\end{array}$ & $\begin{array}{c}\text { Constant } \\
\text { Overall }\end{array}$ & $\begin{array}{c}\text { Constant } \\
\text { Imposed }\end{array}$ & $\begin{array}{c}\text { Constant } \\
\text { Alternate }\end{array}$ \\
\hline \hline 3.00 & 2.50 & 2.00 & 4.00 \\
1.50 & 1.50 & 1.50 & 1.60 \\
0.00 & 1.00 & 1.00 & 1.00 \\
-1.50 & 0.70 & 0.50 & 0.73 \\
$3.00^{\mathrm{a}}$ & 2.50 & 2.00 & 4.00 \\
\hline
\end{tabular}

${ }^{\mathrm{a}}$ This condition was a replication of the initial 3.00 condition. 


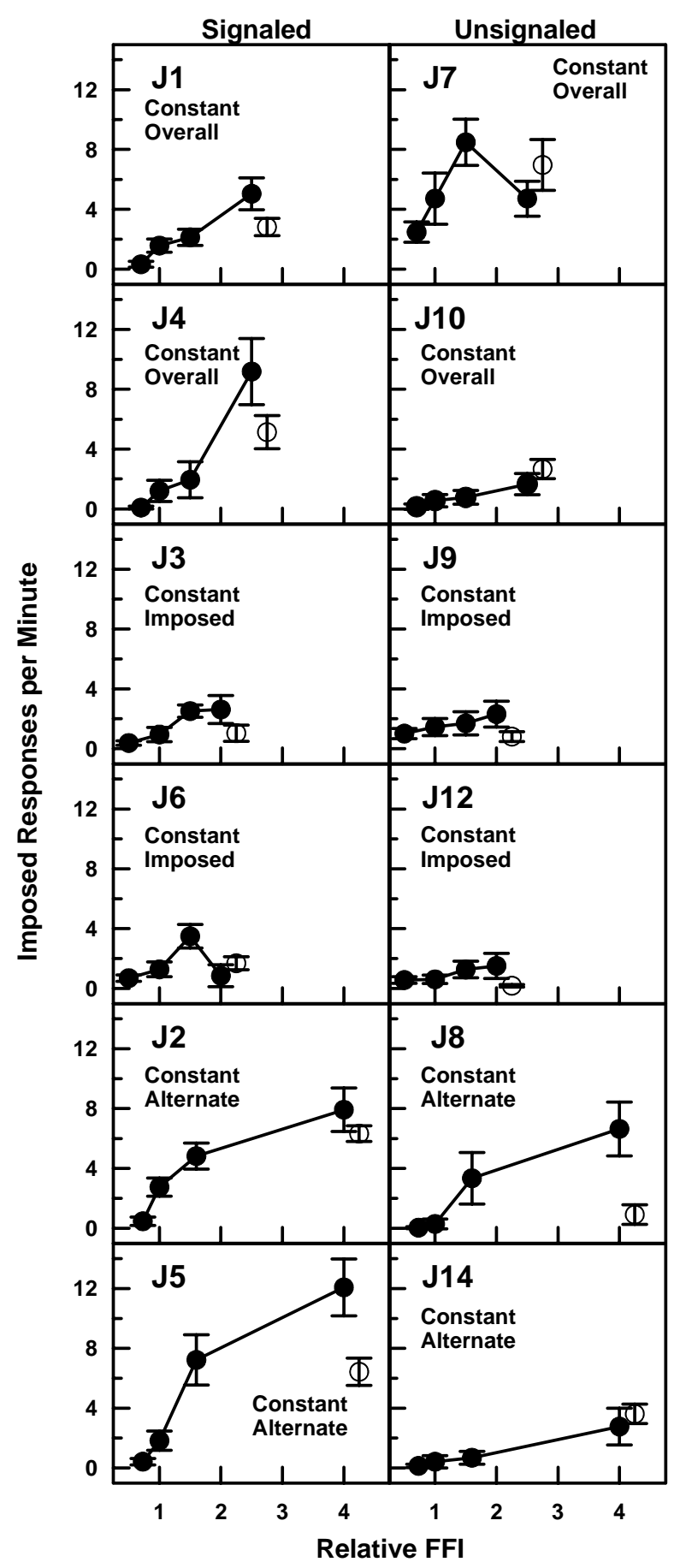

Figure 9. Responses per minute on the imposed schedule as a function of the relative food frequency increase (FFI) afforded by the switch from the imposed to the alternate schedule. Other details are as in Figure 3. 


\section{Discussion}

The current results indicate that the FFI afforded by activating the alternate schedule was a controlling factor, however the effects of FFI depended on the presence of signals and the particular method of programming the schedules. Analyses of group data revealed a significant effect of signaling the imposed and alternate schedules. Reliable changes as a function of FFI were found in the signaled group, but not in the unsignaled group. Additionally, there was a significant effect of the Constancy Variable. Reliable changes as a function of FFI were found in the Constant Overall and Constant Alternate groups, but not in the Constant Imposed group. Results for individual rats confirm these findings. In the signaled group, four of the six rats (Rats J1, J4, J2, and J5) showed clear and convincing effects of FFI. In the unsignaled group, only Rats J7 and J14 showed clear effects of FFI. Other rats showed either weak effects or no effect of FFI. One of the more striking effects seen in individual results was the effect of holding pellet rates constant on the imposed schedule. Regardless of the presence or absence of signals, none of the rats in the Constant Imposed group showed an effect of FFI.

The effects of the Constancy Variable seem to center around pellet rates in the imposed schedule. For the Constant Overall and Constant Alternate groups, pellet rates in the imposed schedule were varied across conditions. For the Constant Imposed group, pellet rates in the imposed schedule were held constant across conditions. The fact that effects of FFI are only evident in the Constant Overall and Constant Alternate groups would suggest that pellet rates in the imposed schedule are a critical factor, but the extent to which these pellet rates alone affect responding is unclear. If changes in pellet rates in the imposed schedule were responsible for changes in response rates, then response rates should remain relatively unchanged when the pellet rates are held constant. It is the case that response rates showed minimal changes across 
conditions in the Imposed Constant group, but interpreting this as evidence of control by pellet rates in the imposed schedule is difficult in light of the considerably low response rates in this group.

There is another possible explanation for the effects of the Constancy Variable. Although all rats were exposed to the same absolute FFIs, a consequence of manipulating the Constancy Variable was variation in relative FFIs. Across conditions, rats in the Constant Imposed group experienced small changes in relative FFIs. By contrast, rats in the Constant Overall and Constant Alternate groups experienced larger changes in relative FFIs. Between the groups, the biggest differences in relative FFI occurred in the 3.00 condition, where the relative FFI for the Constant Alternate group (4.00 pellets per min) was twice that of the Constant Imposed group (2.00 pellets per min). The largest differences in response rates also typically occurred in this condition. Hence, differences in relative FFIs might explain the differences in responding among the Constancy Variable groups.

The degree to which the results support the molar account is limited. While FFI was clearly a factor, the effects of signals and the Constancy Variable leave room for possible molecular interpretations of the results. The extent to which the results support both molar and molecular accounts is summarized below.

\section{Support for the Molar Account}

The fact that Rats J7, J14, and to a lesser extent, J10 showed some sensitivity to changes in FFI offers support for the molar account. For Rats J10 and J14, elevated responding only occurred in the 3.00 condition. However, despite being virtually extinguished in the -1.50 condition, responding was recovered in the replication of the 3.00 condition, indicating sensitivity to changes in FFI. Rats J9 and J12 showed no sensitivity to FFI, but the fact that they 
experienced minimal changes in relative FFI (by virtue of being in the Constant Imposed group) might have been a factor. If this were the case, it would not be entirely inconsistent with the molar account because it would be expected that minimal changes in relative FFI should produce minimal behavior. Additionally, analyses of response rates as a function of pellet rates in both the imposed and alternate schedules provided little evidence that responding was maintained by accidental contiguity between individual responses and pellet deliveries.

The critical test of molar control was responding in the absence of signals. At best, the performances of rats in the unsignaled group show limited evidence of sensitivity to changes in rates. Nonetheless, these results are consistent with other findings suggesting possible molar control. For example, Polson and Parsons (1994) exposed humans to contingencies where pressing the right button on a computer mouse was reinforced at a constant probability of .02. In some conditions, presses to the left mouse button increased the probability of reinforcement on the right button to .08 for a period of $15 \mathrm{~s}$. During this 15 -s period, subsequent left-button presses extended the .08 probability period an additional $15 \mathrm{~s}$. Responding on the left button was maintained at steady rates only in conditions where left-button presses raised the probability of reinforcement. McDowell and Wixted (1986) exposed humans to VI schedules that were modified to feature both molar and molecular properties. As mentioned earlier, VI schedules engender lower response rates than VR schedules with equal reinforcement rates. According to the molecular account, the time-based nature of VI schedules increases the likelihood that longer IRTs will be reinforced. According to the molar account, response rates are higher on VR schedules because of the feedback between reinforcement rates and response rates (higher response rates yield higher reinforcement rates). The VI schedules constructed by McDowell and Wixted were enhanced with the molar features of VR schedules such that reinforcement rates 
could increase when response rates increased. They found that response rates on these enhanced VI schedules were identical to, rather than lower than, response rates on VR schedules with the same molar feedback. Conversely, humans (Jacobs \& Hackenberg, 2000) and pigeons (Vaughan \& Miller, 1984) were exposed to VI schedules that produced maximum reinforcement rates at low response rates. Further increases in response rates reduced reinforcement rates, and while neither study produced evidence of sensitivity to the maximum reinforcement rates, some sensitivity was shown to the reduction in reinforcement rates.

Support for the Molecular Account

Although some rats in the unsignaled group showed sensitivity to changes in FFI, the effects were minimal compared to those in the signaled group. The fact that the effects of FFI depended so heavily on the presence of signals provides strong support for the molecular account. The stimulus changes that accompanied schedule changes occurred at discrete moments in time and were temporally contiguous with responses that activated the alternate schedule. Thus, the presence of signals adds a molecular component to the procedure. Results showing sensitivity to signaled changes in pellet rates are consistent with a procedurally similar study. Findley (1958) exposed pigeons to a concurrent VI VI schedule that was arranged on a single response key (food key). The two VI schedules were signaled by the color illuminating the food key. Responses on a second key (switching key) changed the VI schedule in effect on the food key. Not only was responding maintained on the switching key, but response rates on the switching key varied depending on the differences between the reinforcement rates of the two VI schedules on the food key.

Signals may have had their effect by enhancing the discriminability of the imposed and alternate schedules. Both individual and group results showed that rats in the signaled group 
discriminated the changes in the schedules, whereas the unsignaled group did not. As such, these results are consistent with findings in humans (Madden \& Perone, 1999) and pigeons (e.g., Commons, 1979; Davison, 1996; Davison \& Jenkins, 1985) indicating that sensitivity to reinforcement rates on choice procedures is enhanced when the two schedules can be discriminated.

The effect of the Constancy Variable, particularly in terms of the changes it produced in relative FFI, might also provide support for the molecular account. Minimal responding occurred when the relative FFI was small; whereas response rates were highest when relative FFIs were large. As discussed earlier, these findings don't necessarily contradict the molar account, but they don’t necessarily support it. Consider, for example, the VT schedule values for the Constant Alternate group at an FFI of 3.00 pellets per minute (see Table 1). Activating the alternate schedule changed the interfood interval from $60 \mathrm{~s}$ to $15 \mathrm{~s}$. At the same absolute FFI, the interfood interval for the Constant Imposed Group changed from 20 s to 10 s. For the Constant Alternate group, the change from the imposed to the alternate schedule was accompanied by a rather large change in interfood intervals. The abrupt change from relatively long to relatively short interfood intervals could conceivably be contacted within a few pellet deliveries, and thus may have been sufficient to maintain responding. This is not the case for the Constant Alternate group, as the differences between imposed and alternate interfood intervals were minor.

Baron and Perone (2001) raised a similar issue regarding the Herrnstein and Hineline (1966) study of shock-frequency reduction. One of Herrnstein and Hineline’s conditions arranged intershock intervals as high as $4 \mathrm{~s}$ in the imposed schedule. Activating the alternate schedule then decreased the intershock interval to $20 \mathrm{~s}$. The change in the environment before and after a response was characterized by drastic changes in intershock intervals that could be 
contacted in a brief, arguably molecular, time frame. In this regard, a comparison can be made between the Herrnstein and Hineline study and Myers and Perone’s (1998) study of shockfrequency reduction. Myers and Perone’s procedure was similar to Herrnstein and Hineline’s with the exception that the shock rates were much lower. The range of intershock intervals used by Myers and Perone was approximately 38 s to 600 s. These intervals encompass a time frame more in line with the molar account, and reduce the likelihood that responses are accompanied by large changes in intershock intervals. Contrary to Herrnstein and Hineline, Myers and Perone failed to find evidence of control by shock- frequency reduction. The present results fall in between those of Herrnstein and Hineline and Myers and Perone. If abrupt changes in interfood intervals are a factor, then it is not surprising that apparent sensitivity to molar contingencies was found in conditions where changes in the interfood intervals (current study) and intershock intervals (Herrnstein and Hineline) were large. In conditions where changes in interfood intervals were subtler, as were the intershock intervals in Myers and Perone’s study, behavior was not sensitive to the molar contingencies.

If this interpretation is correct, then it may provide a better account for the current results than explanations involving simple changes in rate. All rats were exposed to the same absolute changes in food frequency. If changes in absolute FFI alone were sufficient to maintain responding, then differences in how the FFIs were programmed shouldn't have had an effect on responding. The results from the Constancy Variable groups show that they did. Although changes in relative FFI may account for the results, elevated responding typically occurred when rate changes were large enough to potentially be contacted over the course of a few pellet deliveries. As such, there doesn't seem to an advantage in describing the results in terms of rate changes when explaining the results in terms of changes in interfood intervals allows for more 
precise units of analysis that can be placed at specific points in time.

\section{Conclusions}

The previous interpretation of the current results and those obtained by Herrnstein and Hineline (1966) and Myers and Perone (1998) might not be considered strictly molecular because it asserts control by several events that are not temporally contiguous with responding. The emphasis, however, is on the temporal distance between these individual events, rather than the rate at which they occur. Thus, the interpretation is not strictly molar. The interpretation does not require strict contiguity or single response-reinforcer relations as a unit of analysis, but it does limit the temporal distance at which behavior and consequences can influence each other. As such, it falls within an all too common area of overlap between molar and molecular theories (e.g., Bersh, 2001). Control of behavior may lie somewhere in this overlapping region. Several studies illustrate this issue. Critchfield and Lattal (1989) and Gleeson and Lattal (1987) conducted a series of experiments demonstrating that various behaviors in rats could be acquired and maintained with delays to reinforcement as long as $30 \mathrm{~s}$. While these results involve relations between single responses and reinforcers that occurred over a brief span of time, temporal contiguity between the events was absent. Shull, Spear, and Bryson (1981) exposed pigeons to two concurrently available schedules on a single key (food key). A VI schedule was in effect on the food key when the key was illuminated green. Pecks to a second switching key changed the food key color to red. The color of the food key remained red for a fixed period of time, after which the VI schedule was reinstated. When the food key was red, the first reinforcer was delivered following the first response after a fixed interval had elapsed, and subsequent reinforcers were arranged after variable intervals. Switching rates were found to be a diminishing function of the time to the delivery of the first reinforcer after a switch to the "red schedule" (the 
fixed delay to reinforcement was varied across conditions). Subsequent "red schedule” reinforcers also had an effect on switching rates, but the effect rapidly diminished with increases in temporal distances between the first and subsequent reinforcers.

Another line of research (e.g., Baum \& Davison 2004; Landon, Davison, \& Elliffe, 2002) has demonstrated the effects of several reinforcers on preferences in choice situations. In these experiments, pigeons are presented with two response options. A single VI schedule assigned reinforcers to each option according to a predetermined ratio (e.g., 27 reinforcers on one option for every one reinforcer on the other option). Preferences for the two options are examined in terms of the delivery of successive reinforcers to one of the options. Not surprisingly, continuously reinforcing one option produces a strong preference for that option. Delivery of a single reinforcer to the other option produces a robust and immediate shift in preference, but the magnitude of the shift decreases as a function of the number of successive reinforcers delivered to the previous option. These findings indicated that preference was a function of several reinforcers, which extends beyond the window of a strict molar account. The effects of previous reinforcers, however, were short-lived, with the effect drastically diminished after two or three reinforcers. This suggests a limited time frame for the effects of multiple reinforcers on current behavior, a finding not entirely in line with a strict molar account. Neuman, Ahearn, and Hineline (1997, 2000) also found lingering effects of several reinforcers that could not be accounted for in strict molar or molecular terms.

In summary, sensitivity to changes in FFI was minimal in the absence of signals, a molecular variable. As such, the molar account is not well supported by the current results. The changes in response rates as a function of the Constancy Variable also present problems for the molar account because the way in which the absolute FFIs were arranged should not have 
affected behavior as it did if the absolute changes food frequencies were sufficient to maintain responding. An interpretation of the effects of the Constancy Variable was suggested in terms of the relative FFIs generated by manipulating the variable. It was suggested that higher relative FFIs produced differences in imposed and alternate interfood intervals that were drastic enough to be contacted shortly following the switch between the schedules. This interpretation is neither strictly molecular nor molar.

There are limitations to interpreting the results in such a way because relative FFIs and their accompanying interfood intervals were not an intentional independent variable. Instead, relative FFIs were a by-product of manipulating the Constancy Variable. As such, the effects of relative FFI suggest a direction for future research. Holding the absolute FFI constant while manipulating the relative FFI might shed some light on the conditions under which FFI comes to control responding in the absence of signals. Additionally, pellet rates in the imposed and alternate schedules can be held constant across a variety of levels in an attempt to understand the relative contributions of pre- and post-response food delivery. These same issues can be extended to studies of shock-frequency reduction for a more comprehensive analysis. Studies such as these may shed some light on whether or not behavior is under the control of molar or molecular contingencies or, as several of the previously mentioned studies suggest, contingencies that lie somewhere in between. 


\section{References}

Anger, D. (1963). The role of temporal discriminations in the reinforcement of Sidman avoidance behavior. Journal of the Experimental Analysis of Behavior, 6, 477-506.

Baron, A., \& Perone, M. (2001). Explaining avoidance: Two factors are still better than one. Journal of the Experimental Analysis of Behavior, 75, 357-361.

Baum, W. M. (1973). The correlation-based law of effect. Journal of the Experimental Analysis of Behavior, 20, 137-153.

Baum, W. M. (1974). On two types of deviations from the matching law: Bias and undermatching. Journal of the Experimental Analysis of Behavior, 22, 231-242.

Baum, W. M. (1981). Optimization and the matching law as accounts of insrumental behavior. Journal of the Experimental Analysis of Behavior, 36, 387-403.

Baum W. M. (1989). Quantitative prediction and molar description of the environment. The Behavior Analyst, 12, 167-176.

Baum, W. M. \& Davison, M. (2004). Choice in a variable environment: Visit patterns in the dynamics of choice. Journal of Experimental Analysis of Behavior, 81, 85-127.

Bersh, P. J. (2001). The molarity of molecular theory and the molecularity of molar theory. Journal of the Experimental Analysis of Behavior, 75, 348-350.

Commons, M. L. (1979). Decision rules and signal detectability in a reinforcement-density discrimination. Journal of the Experimental Analysis of Behavior, 32, 101-120.

Critchfield, T. S., \& Lattal, K. A. (1993). Acquisition of a spatially defined operant with delayed reinforcement. Journal of the Experimental Analysis of Behavior, 59, 373-387.

Davison, M. (1996). Stimulus effects on behavior allocation in three-alternative choice. Journal of the Experimental Analysis of Behavior, 66, 149-168. 
Davison, M., \& Jenkins, P. E. (1985). Stimulus discriminability, contingency discriminability, and schedule performance. Animal Learning \& Behavior, 13, 77-84.

de Villiers, P. A. (1972). Reinforcement and response rate interaction in multiple randominterval avoidance schedules. Journal of the Experimental Analysis of Behavior, 18, 499507.

de Villiers, P. A. \& Herrnstein, R. J. (1976). Toward a law of response strength. Psychological Bulletin, 83, 1131-1153.

Dinsmoor, J. A. (2001). Stimuli inevitably generated by behavior that avoids electric shock are inherently reinforcing. Journal of the Experimental Analysis of Behavior, 75, 311-333.

Dinsmoor, J. A. \& Sears, G. W. (1973). Control of avoidance by a response-produced stimulus. Learning and Motivation, 4, 284-293.

Findley, J. D. (1958). Preference and switching under concurrent scheduling. Journal of the Experimental Analysis of Behavior, 1, 123-144.

Fleshler, M., \& Hoffman, H. S. (1962). A progression for generating variable-interval schedules. Journal of the Experimental Analysis of Behavior, 5, 529-530.

Herrnstein, R. J. (1961). Relative and absolute strength of response as a function of frequency of reinforcement. Journal of the Experimental Analysis of Behavior, 4, 267-272.

Herrnstein, R. J. (1997). The matching law: Papers in psychology and economics. (Rachlin, H., \& Laibson, D. I., Eds.). New York: Russell Sage Foundation.

Herrnstein, R. J., \& Hineline, P. N. (1966). Negative reinforcement as shock-frequency reduction. Journal of the Experimental Analysis of Behavior, 9, 421-430.

Jacobs, E. A., \& Hackenberg, T. D. (2000). Human performance on negative slope schedules of points exchangeable for money: A failure of molar maximization. Journal of the 
Experimental Analysis of Behavior, 73, 241-260.

Keppel, G. (1991). Design and analysis: A researcher's handbook (3 ${ }^{\text {rd }}$ ed.). Upper Saddle River, NJ: Prentice-Hall.

Landon, J., Davison, M., \& Elliffe, D. (2002). Concurrent schedules: Short- and long-term effects of reinforcers. Journal of the Experimental Analysis of Behavior, 77, 257-271.

Lattal, K.A., \& Gleeson, S. (1990). Response acquisition with delayed reinforcement. Journal of Experimental Psychology: Animal Behavior Processes, 16, 27-39.

Madden, G. J., \& Perone, M. (1999). Human sensitivity to concurrent schedules of reinforcement: Effects of observing schedule-correlated stimuli. Journal of the Experimental Analysis of Behavior, 71, 303-318.

McDowell, J. J., \& Wixted, J. T. (1986). Variable-ratio schedules as variable-interval schedules with linear feedback loops. Journal of the Experimental Analysis of Behavior, 46, 315329.

Myers, T., \& Perone, M. (1998, May). Testing the limits of shock-frequency reduction: Two systematic replications of Herrnstein and Hineline (1966). In M. Perone (Chair), Multiple Scales of Analysis: Experimental Studies of Sensitivity to Short-Term and LongTerm Environment-Behavior Relations. Symposium conducted at the meeting of the Association for Behavior Analysis, Orlando, FL.

Neuman, P., Ahearn, W. H., \& Hineline, P. N. (1997). Pigeons' choices between fixed-ratio and geometrically escalating schedules. Journal of the Experimental Analysis of Behavior, 68, 357-374.

Neuman, P., Ahearn, W. H., \& Hineline, P. N. (2000). Pigeons' choices between fixed- ratio and linear or geometric escalating schedules. Journal of the Experimental Analysis of 
Behavior, 73, 93-102.

Peele, D. B., Casey, J., \& Silberberg, A. (1984). Primacy of interresponse-time reinforcement in accounting for rate differences under variable-ratio and variable-interval schedules. Journal of Experimental Psychology: Animal Behavior Processes, 10, 149-167.

Platt, J. R. (1979). Interresponse-time shaping by variable-interval-like interresponse-time reinforcement contingencies. Journal of the Experimental Analysis of Behavior, 31, 3-14.

Polson, D. A. D., \& Parsons, J. A. (1994). Precurrent contingencies: Behavior reinforced by altering reinforcement probability for other behavior. Journal of the Experimental Analysis of Behavior, 61, 427-439.

Reed, P., Soh, M., Hildebrandt, T., DeJongh, J., \& Shek, W. Y. (2000). Free-operant performance on variable interval schedules with a linear feedback loop: No evidence for molar sensitivities in rats. Journal of Experimental Psychology: Animal Behavior Processes, 26, 416-427.

Shimp, C. P. (1966). Probabilistically reinforced choice behavior in pigeons. Journal of the Experimental Analysis of Behavior, 9, 443-455.

Shimp, C. P. (1969). Optimal behavior in free-operant experiments. Psychological Review, 76, 97-112.

Sidman, M. (1953). Two temporal parameters of the maintenance of avoidance behavior by the white rat. Journal of Comparative and Physiological Psychology, 46, 253-261.

Shull, R. L., Spear, D. J., \& Bryson, A. E. (1981). Delay or rate of food delivery as a determiner of response rate. Journal of the Experimental Analysis of Behavior, 35, 129-143.

Skinner, B. F. (1938). The behavior of organisms. New York: Appleton-Century-Crofts. 
Staddon, J. E. R., Hinson, J. M., \& Kram, R. (1981). Optimal choice. Journal of the Experimental Analysis of Behavior, 35, 397-412.

Vaughan, W., Jr., \& Miller, H. L., Jr. (1984). Optimization versus response-strength accounts of behavior. Journal of the Experimental Analysis of Behavior, 42, 337-348. 


\section{Appendix}

Programmed pellet rates and mean obtained pellet rates (in pellets per minute) for the imposed and alternate schedules. Standard deviations are in parentheses. Rats are grouped according to the aspect of pellet rate held constant (Constant Overall, Constant Imposed, and Constant Alternate).

\begin{tabular}{|c|c|c|c|c|c|c|c|c|c|}
\hline \multicolumn{10}{|c|}{ Constant Overall } \\
\hline \multirow{2}{*}{$\begin{array}{c}\text { Imposed } \\
\text { Scheduled }\end{array}$} & \multicolumn{4}{|c|}{ Imposed Obtained } & \multirow{2}{*}{$\begin{array}{l}\text { Alternate } \\
\text { Scheduled }\end{array}$} & \multicolumn{4}{|c|}{ Alternate Obtained } \\
\hline & $\mathrm{J} 1^{\mathrm{a}}$ & $\mathrm{J} 4^{\mathrm{a}}$ & J7 & $\mathrm{J} 10$ & & $\mathrm{~J} 1^{\mathrm{a}}$ & $\mathrm{J} 4^{\mathrm{a}}$ & J7 & $\mathrm{J} 10$ \\
\hline 2.00 & $2.03(0.25)$ & $2.24(0.40)$ & $2.14(0.21)$ & $2.16(0.25)$ & 5.00 & $5.06(0.22)$ & $5.03(0.15)$ & $4.86(0.22)$ & $5.22(0.33)$ \\
\hline 3.00 & $2.95(0.21)$ & $3.02(0.30)$ & $3.00(0.26)$ & $3.00(0.19)$ & 4.50 & $4.66(0.38)$ & $4.51(0.59)$ & $4.53(0.25)$ & 5.18 (1.29) \\
\hline 4.00 & $4.00(0.27)$ & $4.13(0.17)$ & $3.90(0.27)$ & $4.11(0.20)$ & 4.00 & $4.13(0.64)$ & 3.91 (1.19) & $3.96(0.32)$ & $4.13(1.65)$ \\
\hline 5.00 & $5.08(0.16)$ & $5.05(0.06)$ & $5.17(0.13)$ & $5.09(0.12)$ & 3.50 & $3.08(2.32)$ & $1.51(2.21)$ & $3.57(0.35)$ & $1.08(1.76)$ \\
\hline $2.00^{\mathrm{b}}$ & $2.11(0.24)$ & $2.09(0.23)$ & $1.97(0.19)$ & $2.08(0.21)$ & $5.00^{\mathrm{b}}$ & $4.98(0.16)$ & $5.08(0.21)$ & $4.93(0.25)$ & $5.12(0.21)$ \\
\hline \multicolumn{10}{|c|}{ Constant Imposed } \\
\hline Imposed & \multicolumn{4}{|c|}{ Imposed Obtained } & Alternate & \multicolumn{4}{|c|}{ Alternate Obtained } \\
\hline Scheduled & $\mathrm{J}^{\mathrm{a}}$ & $J 6^{a}$ & $\mathrm{~J} 9$ & $\mathrm{~J} 12$ & Scheduled & $\mathrm{J}^{\mathrm{a}}$ & $J 6^{a}$ & J9 & $\mathrm{J} 12$ \\
\hline 3.00 & $2.81(0.26)$ & $2.96(0.13)$ & $2.85(0.33)$ & $2.88(0.35)$ & 6.00 & $6.01(0.52)$ & $5.63(1.45)$ & $5.85(0.53)$ & $6.02(0.59)$ \\
\hline 3.00 & $2.83(0.20)$ & $2.90(0.19)$ & $3.04(0.10)$ & $3.06(0.12)$ & 4.50 & $4.64(0.28)$ & $4.66(0.43)$ & $4.67(0.40)$ & $4.73(0.38)$ \\
\hline 3.00 & $3.06(0.14)$ & $2.87(0.17)$ & $3.05(0.19)$ & $3.04(0.10)$ & 3.00 & $2.78(0.45)$ & $2.79(0.37)$ & $2.88(0.35)$ & $2.73(0.67)$ \\
\hline 3.00 & $3.08(0.14)$ & $2.99(0.09)$ & $2.95(0.07)$ & $2.97(0.10)$ & 1.50 & $1.40(0.62)$ & $1.82(0.69)$ & $1.75(0.73)$ & $1.72(0.81)$ \\
\hline $3.00^{\mathrm{b}}$ & $2.97(0.16)$ & $2.84(0.25)$ & $2.99(0.14)$ & $3.03(0.17)$ & $6.00^{\mathrm{b}}$ & $6.13(0.53)$ & $5.95(0.39)$ & $5.51(0.91)$ & $5.88(1.94)$ \\
\hline \multicolumn{10}{|c|}{ Constant Alternate } \\
\hline Imposed & \multicolumn{4}{|c|}{ Imposed Obtained } & Alternate & \multicolumn{4}{|c|}{ Alternate Obtained } \\
\hline Scheduled & $\mathrm{J} 2^{\mathrm{a}}$ & $\mathrm{J} 5^{\mathrm{a}}$ & $\mathrm{J} 8$ & $\mathrm{~J} 14$ & Scheduled & $\mathrm{J}^{\mathrm{a}}$ & $\mathrm{J}^{\mathrm{a}}$ & $\mathrm{J} 8$ & $\mathrm{~J} 14$ \\
\hline 1.00 & $1.11(0.27)$ & $1.05(0.19)$ & $1.09(0.26)$ & $1.09(0.16)$ & 4.00 & $4.03(0.24)$ & $3.98(0.22)$ & $4.05(0.20)$ & $4.12(0.29)$ \\
\hline 2.50 & $2.45(0.18)$ & $2.44(0.24)$ & $2.52(0.15)$ & $2.46(0.13)$ & 4.00 & $3.93(0.21)$ & $3.99(0.28)$ & $3.99(0.38)$ & $3.92(0.49)$ \\
\hline 4.00 & $4.10(0.31)$ & $4.01(0.27)$ & $4.04(0.21)$ & $4.09(0.23)$ & 4.00 & $4.13(0.51)$ & $3.89(0.34)$ & $1.65(1.88)$ & $4.62(2.22)$ \\
\hline 5.50 & $5.44(0.19)$ & $5.41(0.24)$ & $5.43(0.23)$ & $5.52(0.26)$ & 4.00 & 3.32 (1.98) & 3.78 (1.05) & $1.13(2.53)$ & $3.16(2.80)$ \\
\hline $1.00^{\mathrm{b}}$ & $1.45(1.26)$ & $0.99(0.23)$ & $1.02(0.08)$ & $0.99(0.27)$ & $4.00^{\mathrm{b}}$ & $3.66(0.88)$ & $4.00(0.22)$ & $3.89(0.60)$ & $4.07(0.24)$ \\
\hline
\end{tabular}

${ }^{a}$ These rats are in the signaled group. ${ }^{\mathrm{b}}$ These conditions are replications of the 3.00 condition. 